\title{
Attenuation Correction of X-Band Radar Reflectivity Using Adjacent Multiple Microwave Links
}

\author{
Min-Seong Kim ${ }^{1}$ and Byung Hyuk Kwon ${ }^{2, *}$ \\ 1 Geo-Sciences Institute, Pukyong National University, 45, Yongso-Ro, Nam-Gu, Busan 48513, Korea; \\ minseongkim@pknu.ac.kr \\ 2 Department of Environmental Atmospheric Sciences, Pukyong National University, 45, Yongso-Ro, Nam-Gu, \\ Busan 48513, Korea \\ * Correspondence: bhkwon@pknu.ac.kr; Tel.: +82-(51)-629-6644
}

Received: 24 April 2020; Accepted: 30 June 2020; Published: 3 July 2020

check for updates

\begin{abstract}
Rain attenuation can hinder the implementation of quantitative precipitation estimations using X-band weather radar. Numerous studies have been conducted on correcting the attenuation of radar reflectivity by utilizing a dual-polarimetric radar and an arbitrary-oriented microwave link; however, there is a need to optimize the required number of microwave links and their locations. In this study, we tested four attenuation correction methods and proposed a novel algorithm based on the sole use of adjacent multiple microwave links. The attenuation of the X-band radar reflectivity was corrected by performing forward iterations at each link, and the correction coefficients were statistically analyzed to reduce the instability problem. The algorithms of each method were evaluated by studying the cases of convective and stratiform rainfall, and then validated by comparing the corrected reflectivity of the X-band radar with the qualitatively controlled reflectivity of the S-band radar. The new method was as efficient as the conventional method based on the specific differential phase of dual-polarimetric radar. Furthermore, the correction coefficient was more effectively optimized and stabilized using seven microwave links rather than a single link, and no further independent reference data were required. In addition, the attenuation correction also accounted for spatiotemporal differentiation depending on the rainfall type, and could recover the physical structure of the rainfall. The method developed herein can facilitate estimations of quantitative rainfall in developing countries where dual-polarization weather radars are not common. The exploitation of microwave link data is a promising method for rainfall remote sensing.
\end{abstract}

Keywords: X-band dual-polarimetric radar; radar attenuation correction; multiple microwave links; COMS; S-band radar reflectivity

\section{Introduction}

Low-cost, terrestrial, and commercial microwave links and earth-satellite systems are based on the principle that atmospheric attenuation, which is caused by rain and encountered along each transmission path, can be utilized to determine the path-averaged rate of rainfall [1]. Rain-induced attenuation is a vital step that must be considered when analyzing microwave satellite communication links [2], and it can be estimated utilizing Tropical Rainfall Measuring Mission (TRMM) data [3]. Atlas and Banks [4] investigated two factors that cause attenuation: First, the attenuation caused by precipitation that affects the propagation of electromagnetic waves; second, the received power of a radar is inversely proportional to the square of range. Short wavelength X-band radars provide several advantages over long wavelength radars, such as S- and C-bands, including a finer resolution with a smaller-sized antenna, lower costs, and greater mobility. In addition, since the launch of the Center for 
Collaborative adaptive Sensing of the Atmosphere (CASA) program, short-wavelength radars have been deployed to overcome the coverage limitations of long-wavelength radars [5].

However, the impact of rainfall-induced attenuation on the propagation of electromagnetic waves on a short wavelength (X-band) is one of the main factors affecting the quantitative precipitation estimation of weather radar. Several methods have been proposed to correct attenuated radar reflectivity. For a dual-polarimetric radar, these attenuation correction methods are based on the differential propagation phase, $\phi_{D P}$, being almost linearly proportional to the cumulative attenuation in radar frequencies. For example, Testud et al. [6] suggested an attenuation correction method for a dual-polarimetric radar that assumed a fixed proportionality constant, $\alpha$, of the dependence of specific attenuation, $A_{H}$, on the specific differential phase, $K_{D P}$. However, the dual-polarimetric radar method (DPRm) is sensitive to the proportionality constant, $\alpha\left(=A_{H} / K_{D P}\right)$. In this respect, Bringi et al. [7] proposed a method, referred to as the self-consistent method (SCm), in which the optimal proportionality constant of $A_{H} / K_{D P}$ is estimated by comparing the measured $\phi_{D P}$ with the calculated $\phi_{D P}$. Based on the SCm, Park et al. [5] then extended the method to the X-band dual-polarimetric radar, and Kim et al. [8] corrected the differential reflectivity, $Z_{D R}$, using horizontal and vertical reflectivity $\left(Z_{H} / Z_{V}\right)$ via the $\mathrm{SCm}$.

A microwave link consists of a receiver that continuously receives pulsed power from a transmitter along the line of sight radio path. Microwave links are widely spread across countries and are used for near-ground rainfall monitoring, as well as for the validation [9] and attenuation correction of radar reflectivity. Accordingly, Krämer et al. [10] proposed a method that adopted the attenuation derived from a microwave link with its receiver. They further combined it with an X-band radar. This method was used as a reference for correcting radar data estimations of rainfall without using the dual-polarization factor $\left(\phi_{D P}\right)$, and it was based on the relationship between the attenuation factor, $A_{H}$, and reflectivity, $Z_{H^{\prime}},\left(A_{H}=a Z_{H}{ }^{b}\right)$. Rahimi et al. [11] proposed a backward-iterative attenuation correction method that imposed a microwave link attenuation constraint. Furthermore, Trömel et al. [12] reported that microwave link networks exhibit a high spatial density in many countries and that microwave links are useful to optimize the ratio of $A_{H} / K_{D P}$ in the radar radial direction. However, the microwave link used in these methods must be situated along the radial direction of the radar, which restrains the applications of microwave links for correcting radar attenuation.

Furthermore, Zhang et al. [13] presented a new method based on the DPRm for correcting the attenuation of radar reflectivity using a dual-polarimetric radar and an arbitrary-oriented microwave link. This method can be used to broaden the application scope of microwave links in the attenuation correction of radar reflectivity. However, many microwave links are required to enable the correction of attenuated radar reflectivity from all radar radials. This method also requires further independent reference data, such as that from a dual-polarimetric radar.

In the empirical relationship between the attenuation factor, $A_{H}$, and reflectivity, $Z_{H}{ }^{\prime}$, or $K_{D P}$ $\left(A_{H}=a Z_{H}^{b}\right.$ or $\left.\alpha K_{D P}{ }^{c}\right), a, b, \alpha$, and $c$ are the empirical correction coefficients. It is critical to optimize the correction coefficients $a$ and $\alpha$ to improve the effectiveness of radar attenuation correction methods, because these coefficients vary widely with respect to the drop size distribution and drop temperature. Thus, we propose the use of a modified method that employs seven microwave links to primarily estimate the optimal correction coefficient, $a$, when an attenuation reference cannot be provided by one of the microwave links because of heavy rainfall [13]. This method effectively reduces any instability problems that have been reported in previous methods as it uses multiple adjacent microwave links. The attenuation correction can account for spatiotemporal differentiation depending on the rainfall type, and it also recovers the physical structure of the rainfall in accordance with the rapidly changing spatial and temporal variations as well as the spatial heterogeneity.

Chandrasekar et al. [14] reported that under Rayleigh scattering assumptions, radar reflectivity will not change in accordance with the radar frequency. However, the Rayleigh scattering assumptions are not strictly valid with respect to X-band. Hence, we converted the S-band radar reflectivity to the intrinsic reflectivity in the X-band using an empirical conversion method [15] and changed the 
elevation angles of the S-band radar from $0^{\circ}$ to $1.68^{\circ}$ to identify the smallest differences between radar beam heights.

\section{Materials}

Since 2013, the dual-polarization X-band weather radar (RXM-25, Ridgeline Instruments, USA) has been operated by the Korea Institute of Civil Engineering and Building Technology (KICT) at Goyang-si, Gyeonggi-do Province ( $\left.37.67^{\circ} \mathrm{N}, 126.74^{\circ} \mathrm{E}\right)$, Korea, to conduct rainfall observations (Figure 1). The X-band radar has a frequency of $9410 \mathrm{MHz}$ with horizontal and vertical polarization, and it observes a radius of $40 \mathrm{~km}$ at intervals of spatial resolutions of approximately $60 \mathrm{~m}$; thus, it can observe the total range of Seoul. The antenna uses a parabolic dish with a diameter of $1.8 \mathrm{~m}$ and a beam width of $1.8^{\circ}$, and it has a time resolution of $1 \mathrm{~min}$. The KICT radar simultaneously transmits and receives vertically and horizontally polarized scattered signals. The polarimetric parameter derived from the KICT radar used in this study is the total differential phase, $\phi_{D P}$. The quality of radar data are checked by KICT [16]. $Z_{H}$ and $\phi_{D P}$ were retrieved by KICT at an elevation angle of $5^{\circ}$ throughout Seoul and its suburbs to examine the performance of the attenuation correction of reflectivity.

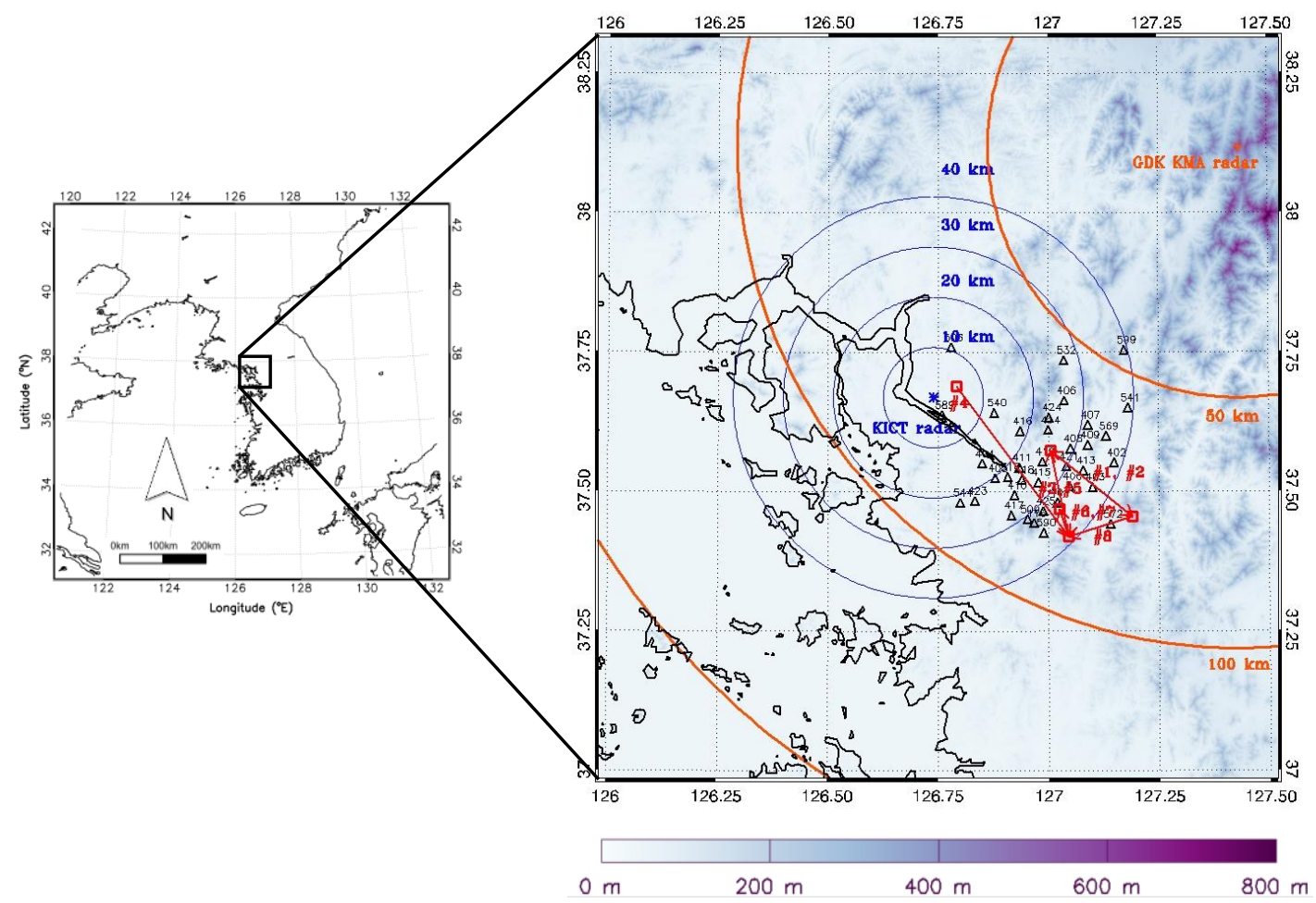

Figure 1. Location of research area (Seoul) in Korea. Red lines represent microwave links, the orange asterisk symbol represents the Gwangdeoksan (GDK) radar, the blue asterisk represents the Korea Institute of Civil Engineering and Building Technology (KICT) radar, and the black triangles indicate automatic weather stations (AWS) locations.

The Gwangdeoksan radar (GDK) is located close to Seoul, at $45.12 \mathrm{~km}$ northeast of the KICT radar. This single-polarization S-band weather radar (DWSR-8501S/KSDP, EEC, USA) has been operated by the Korea Meteorological Administration (KMA) at Hwacheon-Gun, Kangwon-do province $\left(38.1173^{\circ} \mathrm{N}\right.$, $\left.127.4336^{\circ} \mathrm{E}\right)$, Korea, since 2003. It collects volume scan data every $10 \mathrm{~min}$ and has a frequency of $2887 \mathrm{MHz}$ with horizontal polarization, an effective observational range of about $240 \mathrm{~km}$, and a spatial resolution of $1^{\circ} \times 240 \mathrm{~m}$. Quality control is applied to radar data by KMA [17]. $Z_{H}$ was retrieved at elevation angles of $0^{\circ}, 0.3^{\circ}, 0.6^{\circ}, 1^{\circ}$, and $1.7^{\circ}$ to compare the attenuation correction of KICT reflectivity. The main specifications of the KICT radar are listed in Table 1 along with those of the GDK radar. 
Table 1. Technical specification of radars.

\begin{tabular}{ccc}
\hline & KICT Radar & GDK Radar \\
\hline Band & Dual-polarimetric & Single-polarization \\
Location & $37.67^{\circ} \mathrm{N}, 126.74^{\circ} \mathrm{E}$ & $38.1173^{\circ} \mathrm{N}, 127.4336^{\circ} \mathrm{E}$ \\
Transmitter type & Magnetron & Klystron \\
Frequency & $9410 \pm 30 \mathrm{MHz}$ & $2887 \mathrm{MHz}$ \\
Pulse width & $0.6 \mu \mathrm{sec}$ & $0.8 \mu \mathrm{sec}$ and $4.5 \mu \mathrm{sec}$ \\
Pulse repetition frequency & $2000 \mathrm{~Hz}$ & $250-1200 \mathrm{~Hz}$ \\
Gain & $41 \mathrm{~dB}$ & $45 \mathrm{~dB}$ \\
Beam width & $1.4^{\circ}$ & $1^{\circ}$ \\
Time resolution & $1 \mathrm{~min}$ & $10 \mathrm{~min}$ \\
Spatial resolution & $60 \mathrm{~m} \times 60 \mathrm{~m}$ & $250 \mathrm{~m} \times 250 \mathrm{~m}$ \\
Antenna polarization & Simultaneous H/V & Simultaneous H \\
Effective observation range & $40 \mathrm{~km}$ & $240 \mathrm{~km}$ \\
Antenna diameter & $1.8 \mathrm{~m}$ & $8.5 \mathrm{~m}$ \\
\hline
\end{tabular}

This study uses seven microwave links (located in Seoul, Korea) that are operated at frequencies of $10 \mathrm{GHz}$ or less by the Korea Telecom company. All the antennas of the microwave links are shielded from rain using the hydrophobicity of the outer surface of the planar radome to reduce the additional loss of transmission during rainfall [9]. The characteristics of each microwave link (e.g., frequency, polarization, transmitted power ( $\mathrm{dBm})$, and link length) are shown in Table 2. Each link has a transmitted and received power resolution of $0.01 \mathrm{dBm}$ and a time resolution of $15 \mathrm{~s}$. The microwave links were used to provide attenuation references for calculating radar attenuation along the microwave link paths. The MB microwave link crosses $56^{\circ}$ in the azimuth (from $80^{\circ}$ to $136^{\circ}$ ) of the KICT radar (Table 2).

Table 2. Characteristics of microwave links.

\begin{tabular}{cccccccc}
\hline \multirow{2}{*}{ Link } & $\begin{array}{c}\text { Frequency } \\
\text { (GHz) }\end{array}$ & \multirow{2}{*}{$\begin{array}{c}\text { Nearest } \\
\text { AWS }\end{array}$} & \multicolumn{2}{c}{ Distance $\mathbf{( k m )}$ from KICT } & \multicolumn{2}{c}{ KICT Azimuth $\left.\mathbf{(}^{\circ}\right)$} & \multirow{2}{*}{$\begin{array}{c}\text { Link Length } \\
\text { (km) }\end{array}$} \\
\cline { 5 - 7 } & & Transmitter & Receiver & Transmitter & Receiver & \\
\hline \#1 & 7.75 & 413 & 46.37 & 25.56 & 113 & 110 & 21.1 \\
$\# 2$ & 8.06 & 419 & 25.56 & 46.37 & 110 & 113 & 21.1 \\
$\# 3$ & 7.95 & 421 & 25.80 & 38.50 & 110 & 136 & 17.6 \\
$\# 4$ & 6.23 & 425 & 38.50 & 4.95 & 136 & 80 & 37.4 \\
$\# 5$ & 8.26 & 401 & 38.50 & 25.80 & 136 & 110 & 17.6 \\
$\# 6$ & 6.06 & 401 & 33.66 & 38.49 & 136 & 130 & 5.7 \\
$\# 7$ & 6.32 & 401 & 38.49 & 33.66 & 130 & 136 & 5.7 \\
\hline
\end{tabular}

The Communication, Ocean, and Meteorological Satellite (COMS) was launched on 27 June 2010, and was the first Korean geostationary satellite to be located above the equator (at a longitude of $128.2^{\circ} \mathrm{E}$ ). COMS records observations from five bands (i.e., water vapor, visible, short wave infrared, infrared 1, and infrared 2) every $15 \mathrm{~min}$. The microwave channel is structurally similar to a weather radar, allowing it to indirectly measure rainfall by detecting hydrometeors. COMS Rainfall Intensity (RI), Cloud Type (CT), and Cloud Top Height (CTH) data are calculated by the COMS data processing system and provided by the National Meteorological Satellite Center. The CT data were classified from 0 (undefined or cloud-free) to 10 (high semitransparent high, low, or mid-level cloud) using vertical temperature data collected from the regional data assimilation and prediction system and by measuring the brightness temperature of clouds with an infrared channel. COMS monitors one-third of the earth at longitude $128 \mathrm{E}^{\circ}$, and data are observed up to 96 times a day. The COMS data have a spatial resolution of $4 \times 4 \mathrm{~km}$ and a temporal resolution of $15 \mathrm{~min}$ [18]. 


\section{Methods}

\subsection{Attenuation Correction Using Dual-Polarimetric Radar}

Hitschfeld and Bordan [19] used differential equations, whereby the following parameterization can be constructed to correct the attenuation of single-polarization radar data as follows:

$$
A_{H}=a Z_{h}^{b}=a\left(10^{Z_{H} / 10}\right)^{b}
$$

where $A_{H}$ is the one-way specific attenuation at horizontal polarization $\left(\mathrm{dB} \mathrm{km}^{-1}\right), Z_{H}(\mathrm{dBZ})$ is the intrinsic radar reflectivity on a logarithm scale, and $Z_{h}\left(\mathrm{~mm}^{6} \mathrm{~m}^{-3}\right)$ is on a linear scale. This relationship is often unstable and can be affected by partial beam blockage and improper radar calibration. A more stable approach can be devised using the specific differential phase $K_{D P}$. The $K_{D P}$ is provided by dual-polarimetric radars, whereby the specific attenuation $A_{H}$ can be calculated using the following parameterizations:

$$
A_{H}=\alpha K_{D P^{c}}
$$

where $K_{D P}$ is in deg $\mathrm{km}^{-1}$ and $\alpha$ is in $\mathrm{dB} \mathrm{deg}^{-1}$. The relation (2) is assumed to be linear, which is approximately valid at typical weather radar frequencies [20].

The DPRm [6] facilitates two-way path-integrated horizontal attenuation, $P I A_{2}$, by the total change along a radial through a rain cell. The attenuation is then apportioned according to the distribution of $Z_{H}$ along the radial, making this algorithm significantly more stable than the $A_{H}-K_{D P}$ relation $[20,21]$. The DPRm requires two a priori values: the exponent in the $A_{H}-Z_{H}$ relation [b; see (1)] and the coefficient in the $A_{H}-K_{D P}$ relation [ $\alpha$; see (2)]. The intrinsic radar reflectivity, $Z_{H}$, at a range, $r$, is related to the measured (i.e., attenuated) radar reflectivity, $Z_{H}{ }^{\prime}$, as follows:

$$
\begin{aligned}
Z_{H}(r) & =Z_{H}{ }^{\prime}(r)+2 \int_{0}^{r} A_{H}\left(r^{\prime}\right) d r^{\prime} \\
& =Z_{H}{ }^{\prime}(r)+P I A_{2}(r) .
\end{aligned}
$$

Testud et al. [6] assumed that specific attenuation, $A_{H}$, is determined with a constraint, $P I A_{2}$, that is proportional to the total span of the differential phase shift, $\Delta \phi_{D P}$, in typical radar frequencies:

$$
P I A_{2}=\alpha\left[\phi_{D P}\left(r_{1}\right)-\phi_{D P}\left(r_{0}\right)\right]=\alpha \Delta \phi_{D P}
$$

where $r_{0}$ and $r_{1}$ denote the first and last range of precipitation, respectively. With this constraint, $A_{H}$ can be calculated as

$$
A_{H}(r)=\frac{\left[Z_{H^{\prime}}(r)\right]^{b}\left[10^{\left.0.1 b \alpha \Delta \phi_{D P}-1\right]}\right.}{I\left(r_{0}, r_{1}\right)+\left[10^{\left.0.1 \alpha b \Delta \phi_{D P}-1\right] I\left(r, r_{1}\right)}\right.}
$$

where

$$
\begin{aligned}
& I\left(r_{0}, r_{1}\right)=0.46 b \int_{r_{0}}^{r_{1}}\left[Z_{H}{ }^{\prime}(s)\right]^{b} d s, \\
& I\left(r, r_{1}\right)=0.46 b \int_{r}^{r_{1}}\left[Z_{H}{ }^{\prime}(s)\right]^{b} d s,
\end{aligned}
$$

and $r_{0}<r<r_{1}$. It is necessary to set the coefficient $\alpha$ and exponent $b$ to calculate $A_{H}$ in Equation (5). Both $\alpha$ and $b$ are empirical parameters that can be obtained by a scattering simulation of the raindrop size distribution. Delriu et al. [22] state that $b$ varies from 0.76 to 0.84 at a short wavelength (e.g., in the X-band radar), and $\alpha$ can vary widely with respect to rain drop shape and temperature [23]. Bringi et al. [24] 
observed a linear relationship between $K_{D P}$, and $A_{H}$ when the exponent $b$ in Equation (6) was close to 1. Park et al. [5] noted that $\alpha$ changed from 0.139 to 0.335 at a short wavelength (e.g., in the X-band), and Ryzhkov et al. [25] determined $\alpha$ as 0.14 . Thus, the corrected reflectivity $Z_{H}(r)$ can be obtained using Equations (2)-(5).

However, if $A_{H}(r)$ is calculated using a fixed value of $\alpha$, the calculated $A_{H}(r)$ will have non-ignorable errors that will then affect the radar reflectivity attenuation correction. In this respect, Bringi et al. [7] proposed a self-consistent method that did not set the coefficient $\alpha$ as a fixed value. Furthermore, instead of using a fixed $\alpha$ in the DPRm, which is based on a dual-polarization radar, the method proposed by Zhang et al. [13] estimated the optimal $\alpha$ using an iterative process based on a dual-polarimetric radar measurement with a single microwave link (RSML). In contrast to the weather radar, where there is a factor of $1 \times 10^{-17}$ between the received and transmitted signal power level (which is caused by a small backscatter proportion), the amplitude of the link can be directly measured [26]. Furthermore, the path-integrated attenuation of the microwave link $\left(A_{M L}\right)$ can be calculated based on Kim and Kwon [9]. If the frequency of the weather radar differs from that of the microwave link, the attenuation $\left(A_{M L}\right)$ at the microwave link frequency must be transferred to that at the weather radar frequency $(9410 \mathrm{MHz}), A_{R E F}$ is calculated as follows:

$$
A_{\text {REF }}(r)=A_{M L}(r) * \frac{\text { macrowavefrequency }}{\text { radarfrequency }} .
$$

The initial $\alpha$ value is set to a certain range and can be determined from previous studies, such as the change from 0.139 to 0.335 reported by Park et al. [5]. The mean of the radar-specific attenuation, $\overline{A_{R}}$, along a link path is calculated using Equations (4)-(8).

$$
\overline{A_{R}}=\frac{\sum_{i=1}^{N_{M L}} A_{H}(i)}{N_{M L}}
$$

where $N_{M L}$ is the total number of radar measurements made along the microwave link path. In RSMLm, the minimum initial value $\left(\alpha_{1}=0.1\right)$ and the maximum initial value $\left(\alpha_{2}=0.5\right)$ are set first, and $\overline{A_{R}}$ and $A_{M L}$ are then retrieved with these initial $\alpha$ values using radar measurements and microwave link measurements. The optimal values can be determined by minimizing the cost function $(\delta A)$, which is defined as the difference between $\overline{A_{R}}$ and $A_{R E F}$, using the golden-section search method [27], which is calculated as

$$
\delta A=\left\lceil\overline{A_{R}}-A_{R E F}\right\rceil
$$

The golden-section search method is performed by first selecting two internal points, $\alpha_{3}$ and $\alpha_{4}$, in the interval $\left[\alpha_{1}, \alpha_{2}\right]$. The distance between the left-most endpoint, $\alpha_{1}$ and the right-most internal point, $\alpha_{4}$, is equal to the distance between the left-most internal point, $\alpha_{3}$, and the right-most endpoint, $\alpha_{2}$. Both distances are equal to $0.618\left(\alpha_{2}-\alpha_{1}\right)$. If $\delta A\left(\alpha_{3}\right)>\delta A\left(\alpha_{4}\right)$, the range of $\alpha$ for the next iteration is set to $\left[\alpha_{3}, \alpha_{2}\right]$; otherwise, the range is set to $\left[\alpha_{1}, \alpha_{4}\right]$. Therefore, the range of $\alpha$ is narrowed by a fixed coefficient (0.618) after each iteration. Finally, with the optimized $\alpha$ in Equations (5) and (6), the optimal specific attenuation, $A_{H}$, at each gate of the radar within the azimuth range in which the microwave link cross is retrieved, and the attenuated radar reflectivity can be corrected using Equation (3) [13].

A modified algorithm with a dual-polarimetric radar measurement and adjacent multiple microwave links (RMML) based on the RSMLm was tested. Each individual mean specific attenuation from $\overline{A_{R 1}}$ to $\overline{A_{R 7}}$ along each microwave link path from $A_{R E F 1}$, to $A_{R E F 7}$ was calculated with each respective individual optimal coefficient from $\alpha_{o p t 1}$ to $\alpha_{o p t 7}$. The maximum correction coefficient among the seven optimal coefficients was determined as the final optimal coefficient, $\alpha_{\text {opt }}$, for correcting the radar reflectivity in the convective rainfall case, and the mean correction coefficient was determined in the stratiform rainfall case. This is because stratiform rainfall has relatively more homogeneous and weaker rainfall echoes than convective rainfall. When the microwave link missed a specific attenuation reference, the coefficient was consistently estimated. 


\subsection{Attenuation Correction Using Microwave Link only}

Krämer et al. [10] proposed a correction method implemented using a gate by gate correction with a single microwave link (SML), where the accumulated attenuation is estimated from Equations (1) to (10) at each gate. The specific attenuation is calculated from the measured reflectivity and the sum of the attenuation from the preceding gates. This process is described in (10) where $\Delta r=0.06 \mathrm{~km}$, which is the gate length of the X-band radar. A factor of two is used to consider the two-way attenuation of $\mathrm{X}$-band radar signal experiences as follows:

$$
A_{H}(r)=a \sum_{r=r_{0}}^{N}\left(Z_{H}{ }^{\prime}(r)+\sum_{r=r_{0}}^{N-1} A_{H}(r)\right)^{b} \times 2 \Delta r,
$$

where $N$ is the total number of radar measurements along the microwave link.

In the SML method (SMLm), radar attenuation is calculated over time using optimized $a, b$ coefficients, which provides the minimum attenuation difference between the $\overline{A_{R}}$ and $A_{R E F}$,

$$
\left|\overline{A_{R}}-A_{R E F}\right| \leq A_{\text {Threshold }}
$$

The optimal coefficients $a$ and $b$ are determined when the attenuation differences between $\overline{A_{R}}$ and $A_{\text {REF }}$ are not larger than $A_{\text {Threshold }} \leq 0.25 \mathrm{~dB}$. The forward iterative correction is preferred because it is highly sensitive to the choices of $a$ and $b$. The coefficients are varied in the range of $1 \times 10^{-6} \leq a \leq 1 \times 10^{-3}$ and $0.65 \leq b \leq 1.0$. Gunn and East [28] proposed $(a, b)=\left(4.41 \times 10^{-4}, 0.73\right)$ whereas Delrieu et al. [29] suggested $\left(6.49 \times 10^{-5}, 0.9\right)$. Rahimi et al. [11] suggested a backward iterative attenuation correction method. In this study, $2.0 \times 10^{-4}$ and 0.7 were used as the initial guess values of $a$ and $b$, respectively, to first overestimate the attenuation. The coefficient $a$ is gradually reduced by $\Delta a=1.0 \times 10^{-5}$ until it is stable or $a=3.0 \times 10^{-5}$, but the exponent $b$, remains constant. However, this method is inherently unstable because it is numerically sensitive to clutter echoes, radar calibration problems, and oversimplified assumptions of the attenuation [10]. In addition, the SMLm requires a microwave link that lies along the radar radial direction, which then restrains the applications of arbitrary oriented links. In this study, the MB link is quasi-parallel to the X-band radar ray to provide microwave-specific attenuation. However, the optimal coefficients of the characteristic allocation along the "minute-lines" serves as the basis for the real-time estimation of the coefficient $a$, even in the absence of a microwave link (e.g., an attenuation reference) for each individual radar ray [10].

We propose a novel algorithm that only uses adjacent multiple microwave links and is based on both the SMLm and RMMLm. This multiple microwave links method (MMLm) estimates the specific attenuation by the SMLm and the correction coefficient by the RMMLm. When a microwave link misses a specific attenuation reference, the MMLm can stably estimate the optimized coefficient and correct the attenuation of the X-band radar. The characteristics of the five attenuation correction methods are compared among each other in Figure 2 and Table 3.

\subsection{Assessment of the Performance of Correction Methods}

Snyder et al. [20] reported that reflectivity in the X-band may differ significantly from that in the S-band. The radar reflectivity in the S-band was converted into the intrinsic reflectivity in the $\mathrm{X}$-band using an empirical conversion method [15]. The elevation angles $\left(5^{\circ}, 0^{\circ}\right)$ of the $\mathrm{X}$-band and S-band radars are the lowest elevation angles. The radar beam heights (RBHs) from the beam blockage simulation were retrieved by KICT (X-band) radar at an elevation angle of $5^{\circ}$ and by GDK (S-band) radar at elevation angles of $0^{\circ}, 0.3^{\circ}, 0.6^{\circ}, 1^{\circ}$, and $1.7^{\circ}$ over the 36 AWS sites. We changed the elevation angles of the S-band radar from $0^{\circ}$ to $1.7^{\circ}$ to identify the smallest differences between RBHs. Results showed that the minimum, maximum, median, and average RBH differences between the X-band radar and the S-band radar were $0,1.0,0.1$, and $0.2 \mathrm{~km}$, respectively. 


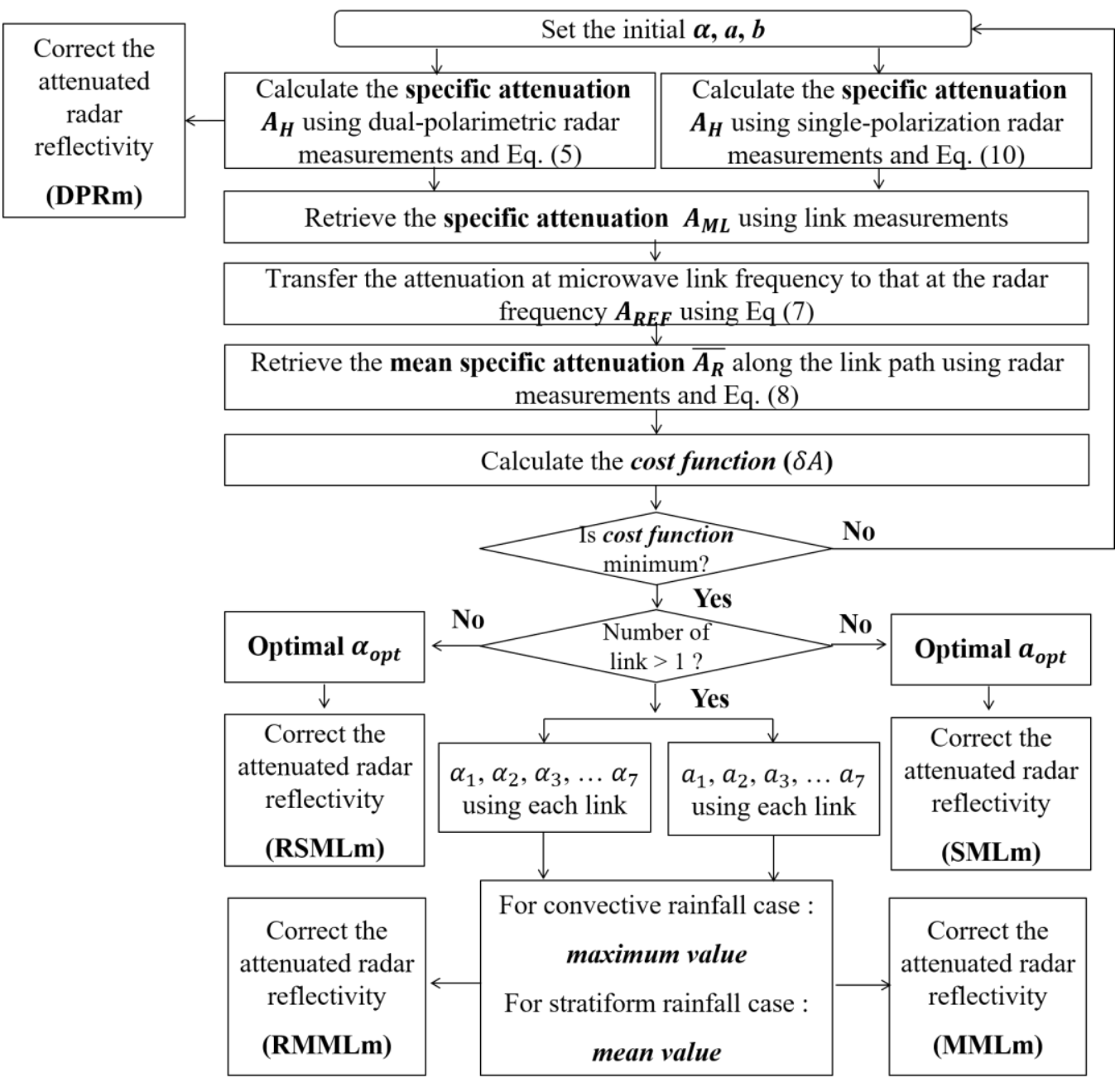

Figure 2. Flow chart of the five attenuation correction methods.

Table 3. Characteristics of the five attenuation correction methods (DPRm: Dual-Polarimetric Radar method, RSMLm: Dual-Polarimetric Radar and Single Microwave Link method, RMMLm: Dual-Polarimetric Radar and Multiple Microwave Link method, SMLm: Single Microwave Link method, MMLm: Multiple Microwave Link method).

\begin{tabular}{|c|c|c|c|c|c|}
\hline Method & DPRm [6] & RSMLm [13] & RMMLm & SMLm [10] & MMLm \\
\hline $\begin{array}{l}\text { Required } \\
\text { Instruments }\end{array}$ & $\begin{array}{l}\text { Dual-Polarimetric } \\
\text { Radar }\end{array}$ & $\begin{array}{l}\text { Dual-Polarimetric } \\
\text { Radar, Single } \\
\text { Microwave link }\end{array}$ & $\begin{array}{l}\text { Dual-Polarimetric } \\
\text { Radar, Multiple } \\
\text { Microwave link }\end{array}$ & $\begin{array}{l}\text { Radar, Single } \\
\text { Microwave Link }\end{array}$ & $\begin{array}{l}\text { Radar, Multiple } \\
\text { Microwave Link }\end{array}$ \\
\hline$A_{H}$ & $\overline{I\left(r_{\text {star }}\right.}$ & $\begin{array}{c}A_{H}(r)= \\
{\left[\frac{\left.Z_{H}^{\prime}(r)\right]^{b}\left[10^{\left.0.1 b \alpha \Delta \phi_{D P}-1\right]}\right.}{\left.{ }^{\prime}, r_{\text {end }}\right)+\left[10^{\left.0.1 \alpha b \Delta \phi_{D P}-1\right] I(r,}\right.}\right.}\end{array}$ & $\frac{}{\left.r_{\text {end }}\right)}$ & \multicolumn{2}{|c|}{$A_{H}(r)=$} \\
\hline$A_{\text {REF }}$ & - & \multicolumn{4}{|c|}{$A_{R E F}=A_{H} * \frac{\text { Link frequency }}{\text { Radar frequency }}$} \\
\hline$\overline{A_{R}}$ & - & \multicolumn{4}{|c|}{$\overline{A_{R}}=\frac{\sum_{i=1}^{N_{M L}} A_{H}(i)}{N_{M L}}\left(\right.$ for SMLm, $\overline{A_{R}}=\sum_{i=1}^{N_{M L}} A_{H}(i)$} \\
\hline $\begin{array}{l}\text { Cost function } \\
\qquad(\delta A)\end{array}$ & - & \multicolumn{4}{|c|}{$\delta A=\left|\overline{A_{R}}-A_{R E F}\right|\left(\right.$ for SMLm, $\left.\delta A=\left|\overline{A_{R}}-A_{R E F}\right| \leq 0.25\right)$} \\
\hline Constant & $\begin{array}{l}\alpha=0.28 \\
b=0.86\end{array}$ & \multicolumn{2}{|r|}{$b=1.036$} & \multicolumn{2}{|r|}{$b=0.9$} \\
\hline $\begin{array}{c}\text { Variable } \\
\text { (initial value) }\end{array}$ & $Z_{H^{\prime}}^{\prime} \phi_{D P}$ & $\alpha\left(\begin{array}{l}\alpha \\
\alpha_{1}\end{array}\right.$ & $\left.\begin{array}{l}\min \\
\max =0.1,\end{array}\right), Z_{H^{\prime}}{ }^{\prime} \phi_{L}$ & 1 & $\begin{array}{l}a_{\min }=0.0001 \\
a_{\max }=90\end{array}$ \\
\hline
\end{tabular}


To assess the performance of the correction methods in the statistical methods, bias (BS), mean error (ME), mean absolute error (MAE), correlation coefficient (CC), and root mean square error (RMSE) between the KICT radar reflectivity and the GDK radar reflectivity were calculated as follows.

$$
\begin{gathered}
\text { Bias }(\mathrm{BS})=\sum_{\mathrm{i}=1}^{\mathrm{N}} \mathrm{KICT} \operatorname{radar}(\mathrm{i}) / \sum_{\mathrm{i}=1}^{\mathrm{N}} \mathrm{GDK} \operatorname{radar}(\mathrm{i}) \\
\text { Mean Error }(\mathrm{ME})=\frac{1}{\mathrm{~N}} \sum_{\mathrm{i}=1}^{\mathrm{N}}(\mathrm{KICT} \operatorname{radar}(\mathrm{i})-\mathrm{GDK} \operatorname{radar}(\mathrm{i})) \\
\text { Mean Absolute Error }(\mathrm{MAE})=\frac{1}{\mathrm{~N}} \sum_{\mathrm{i}=1}^{\mathrm{N}}|\mathrm{KICT} \operatorname{radar}(\mathrm{i})-\mathrm{GDK} \operatorname{radar}(\mathrm{i})|
\end{gathered}
$$

\section{Results}

\subsection{Reflectivity of Convective and Stratiform Rainfall}

To assess the effectiveness of the various $\mathrm{X}$-band radar reflectivity attenuation corrections, a stratiform rainfall case (from 19:21 LST, on 2 May 2016, to 08:50 LST, on 3 May 2016) and a convective rainfall case (from 10:21 LST to 14:50 LST, on 5 July 2016) were investigated. Large differences were observed between the maximum rainfall duration measured using the tipping-bucket rain gauge (966 $\mathrm{min}$ ) and that measured using the rain detector (1383 $\mathrm{min}$ ). This was because the rain gauge could not measure the amount of rain that were less than $0.5 \mathrm{~mm}$ (as it depended on the bucket volume). These differences in the amount of rain indicated that the rainfall was not persistent [9].

Rainfall classification schemes generally depend on the rainfall rate or radar reflectivity because of a lack of detailed dynamic spatial and temporal and microphysical information. Classification schemes using ground-based weather radar can identify [30] areas associated with the bright band [31]. Simple classification schemes (those that provide a threshold for radar reflectivity and the rainfall rate) are used to separate convective rainfall $\left(\geq 40 \mathrm{dBZ}\right.$ or $\left.\geq 10 \mathrm{~mm} \mathrm{~h}^{-1}\right)$ from stratiform rainfall $(<40 \mathrm{dBZ}$ or $<10 \mathrm{~mm} \mathrm{~h}^{-1}$ ) [32], where convective rainfall cases show rapid spatial and temporal variations with spatial heterogeneity. COMS data are also used to compare convective rainfall and stratiform rainfall.

The effectiveness of the five radar attenuation correction methods (DPRm, RSMLm, RMMLm, SMLm, and MMLm) was validated by comparing the corrected X-band radar reflectivity with the S-band radar reflectivity in convective rainfall and stratiform rainfall. Note that the S-band radar reflectivity is assumed to be non-attenuated. In this respect, a strong convective rainfall system swept over Seoul city from west to east on 5 July 2016. The precipitation type was initially convective, but it then developed and became a mixed type precipitation. The spatial distributions of the RI, CTH, and CT during the convective rainfall case are shown in Figure 3. Generally, RI is correlated with CTH. The CTH developed to over $13 \mathrm{~km}$ (Figure 3b) in the study area where the RI was more $10 \mathrm{~mm} \mathrm{~h}^{-1}$ (Figure 3a); this was consistent with the classification schemes. In addition, the CT (Figure 3c) was "very high cloud."

A stratiform rainfall event that occurred from 19:21 LST on 2 May 2016 to 08:50 LST on 3 May 2016, was also analyzed to further assess the performance of the attenuation correction methods. The CTH was approximately $5 \mathrm{~km}$ (Figure 2e) in the study area and the RI was less $10 \mathrm{~mm} \mathrm{~h}^{-1}$ (Figure 3d); these results were consistent with the classification schemes [32], and the CT (Figure 3f) was "low cloud."

Figure 4a shows the plan position indicator (PPI) of the X-band radar reflectivity at an elevation of $5^{\circ}$ at 07:00 LST on 5 July 2016, for a single scan prior to attenuation correction, and Figure $4 \mathrm{~b}$ shows the PPI of the S-band radar reflectivity at an elevation of $0^{\circ}$ at the same time. The reflectivity distribution of the X-band radar is evidently different from that of the S-band radar. The X-band radar reflectivity values within $260-10^{\circ}$ and $80-135^{\circ}$ were highly attenuated, and the far range within 
$190-260^{\circ}(30-40 \mathrm{~km})$ was missed owing to the strong attenuation of heavy rain. The maximum X-band radar reflectivity of the convective cores was approximately $35 \mathrm{dBZ}$, whereas the corresponding S-band radar reflectivity was approximately $45 \mathrm{dBZ}$. Figure $4 \mathrm{c}$ shows a scatter plot of the X-band radar reflectivity prior to attenuation correction and the S-band radar reflectivity for the 36 rain gauges within $80-160^{\circ}$. The X-band radar reflectivity prior to the attenuation correction was much lower than that of the S-band radar, the mean error (ME) was $-16.2 \mathrm{~dB}$, and the root mean square error (RMSE) was $17.7 \mathrm{~dB}$.

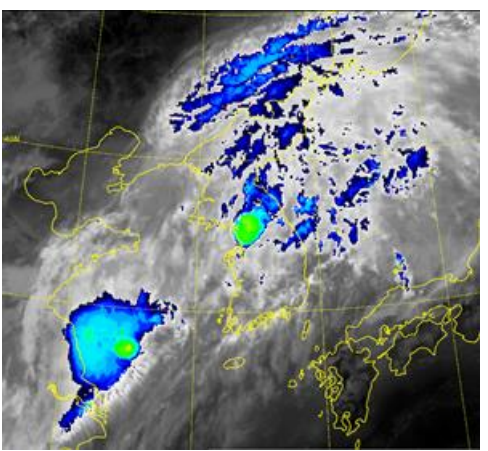

(a)

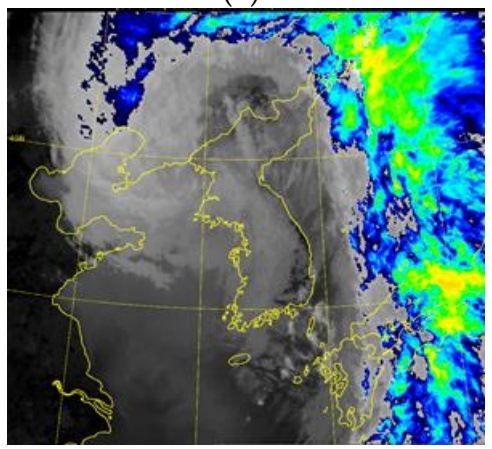

(d)

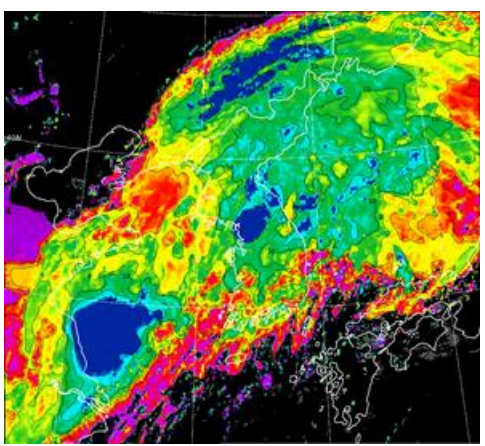

(b)

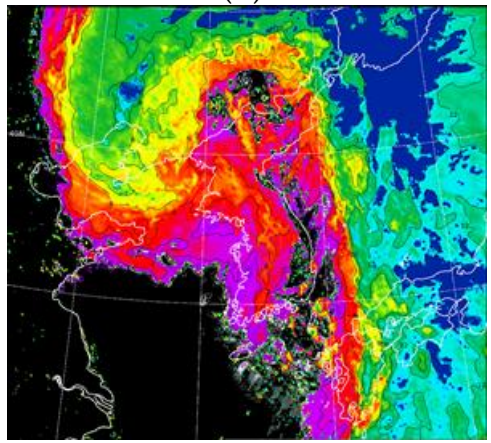

(e)

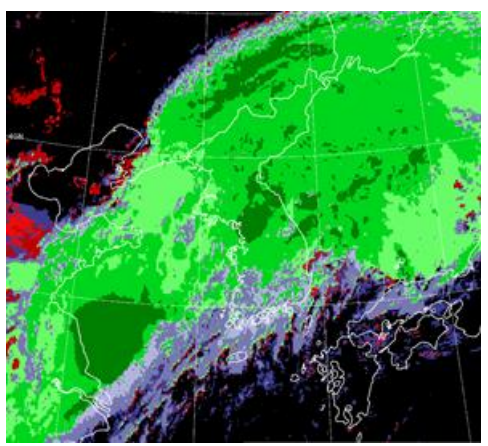

(c)

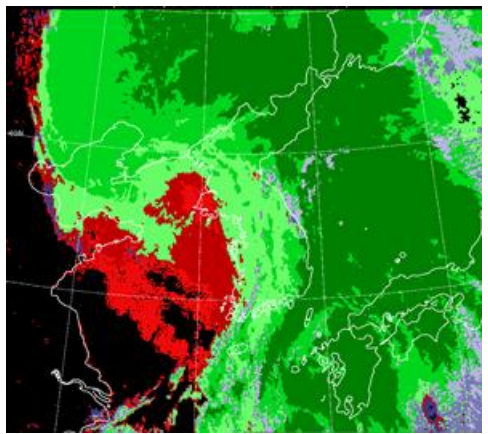

(f)

Figure 3. (a) Rainfall Intensity (RI), (b) Cloud Top Height (CTH), and (c) Cloud Type (CT) during convective rain occurring at 23:15 LST, on 5 July 2016. and (d) RI, (e) CTH, and (f) CT during stratiform rain occurring at 15:30 LST, on 3 May 2016 (provided by the National Meteorological Satellite Center).

Figure $4 \mathrm{~d}$ shows the X-band radar reflectivity field at 22:00 LST, on 2 May 2016, for a single scan prior to the attenuation correction. The range of reflectivity in the stratiform rainfall case was not considerably larger in the convective rainfall case. The maximum reflectivity in the $\mathrm{X}$-band was approximately $29 \mathrm{dBZ}$, whereas the corresponding S-band reflectivity was approximately $38 \mathrm{dBZ}$. Figure $4 \mathrm{f}$ shows that the correlation coefficient (CC) was exceedingly low, and the MAE (8.9 dB) and the RMSE $(10.3 \mathrm{~dB})$ were much lower than those in the convective case. This is because attenuation largely occurs owing to the relatively strong echoes in convective rainfall.

\subsection{Attenuation Correction with a Dual-Polarimetric Radar}

The specific attenuation $\left(A_{H}\right)$ at an elevation of $5^{\circ}$ was calculated by the DPRm at 07:00 LST, on 5 July 2016, and the attenuation correction coefficients were used as fixed values $(\alpha=0.28$ and $b=0.86$ ). The maximum $A_{H}$ was $15 \mathrm{~dB}$ (Figure 5a), and its distribution was utilized to correct the radar reflectivity with (2). After using the DPRm, the X-band radar reflectivity was increased at most azimuth angles in the far range $(30-40 \mathrm{~km})$ of the $X$-band radar. This improved reflectivity was more intense than the S-band radar reflectivity (Figure $5 b$ ), and weak reflectivity in the far range was increased from $20 \mathrm{dBZ}$ to $30 \mathrm{dBZ}$.

To evaluate the performance of the DPRm, Figure $5 \mathrm{c}$ shows a scatter plot of the X-band radar reflectivity after DPRm and S-band radar reflectivity from the 36 rain gauges. A comparison of radar 
reflectivity prior to the attenuation correction and radar reflectivity after DPRm shows that the ME decreased from $-16.2 \mathrm{~dB}$ to $-1.3 \mathrm{~dB}$, the MAE decreased from $16.2 \mathrm{~dB}$ to $7.2 \mathrm{~dB}$, BS increased from 0.5 to 1.0 , and RMSE decreased from $17.7 \mathrm{~dB}$ to $8.7 \mathrm{~dB}$. Although these statistical values were clearly improved, the corrected X-band radar reflectivity significantly deviated from that of S-band radar reflectivity when the echoes were strong. For example, the reflectivity on the far range of the X-band radar was $25 \mathrm{dBZ}$ larger than S-band radar reflectivity. This occurred because $A_{H}$ was calculated with a fixed value of $\alpha$. The calculated $A_{H}$ has non-ignorable errors that in turn affected the radar reflectivity attenuation correction. The $A_{H}$ was overestimated with a sharp increase in $\phi_{D P}$ at azimuth angles of $350-5^{\circ}$, at around $100^{\circ}$, from $170-90^{\circ}$, and at around $290^{\circ}$. This is likely because of contamination caused by the accumulation of errors with the increasing range and broadening of the beam. DPRm is strongly sensitive to the coefficient $\alpha$ with (2) [13]. Estimating $K_{D P}$ from the measured total differential phase shift $\left(\Psi_{D P}\right)$ is challenging because the backscatter differential phase shift causes measurement errors for $\Psi_{D P}$ [33].

The RSMLm determines the time-varying optimal $\alpha_{\text {opt }}$ using an iterative procedure based on incorporating a microwave link-based $A_{M L}$ and a radar-induced $\overline{A_{R}}$. When $A_{H}$ within the azimuth range of $80-145^{\circ}$ parallel to the \#4 microwave link was estimated (Figure $5 \mathrm{~d}$ ), the reflectivity was corrected (Figure 5e), and the corrected reflectivity for the same section at a distance of $30 \mathrm{~km}$ increased by approximately $20 \mathrm{dBZ}$ (Figure 5f). The distribution of $A_{H}$ at 07:00 LST on 5 July 2016, was then calculated using RMMLm, which applied adjacent multiple microwave links (Figure 5g). The time-varying optimal attenuation correction coefficient $\alpha_{\text {opt }}(=0.192)$ was determined as the maximum value among individual $\alpha_{\text {opt } 1}(=0.163), \alpha_{\text {opt2 }}(=0.163), \alpha_{\text {opt3 }}(=0.187), \alpha_{\text {opt } 4}(=0.187), \alpha_{\text {opt5 }}(=0.187), \alpha_{\text {opt6 }}(=0.192)$, and $\alpha_{\text {opt7 }}(=0.192)$. The corrected X-band radar reflectivity on the far range of the X-band radar was increased from $15 \mathrm{dBZ}$ to $30 \mathrm{dBZ}$ compared with the uncorrected $\mathrm{X}$-band reflectivity (Figure $5 \mathrm{~h}$ ), and it was less intense than DPRm.

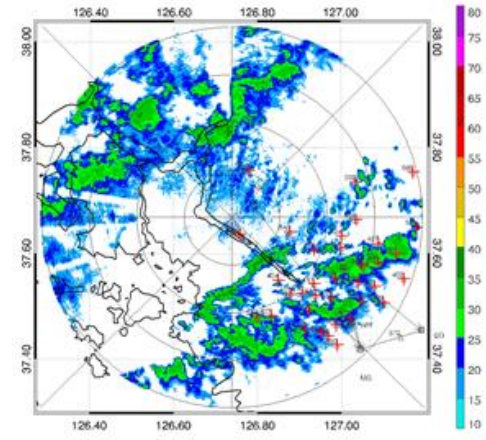

(a)

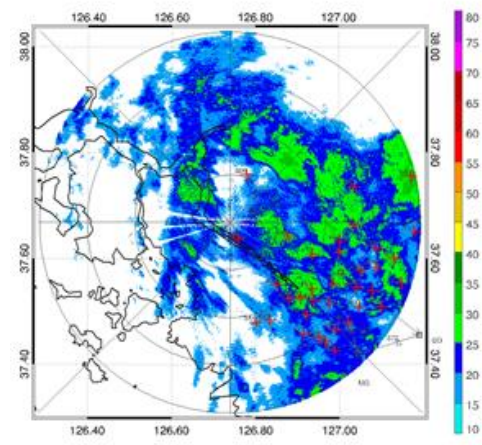

(d)

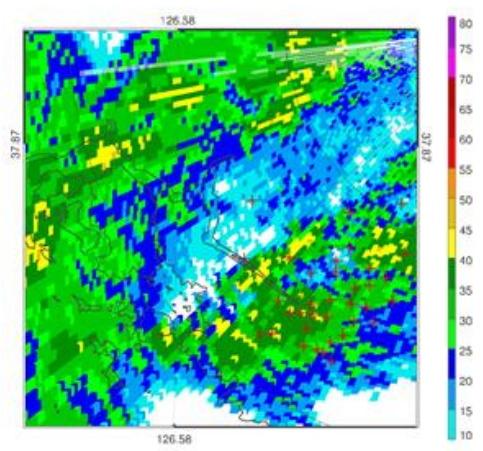

(b)

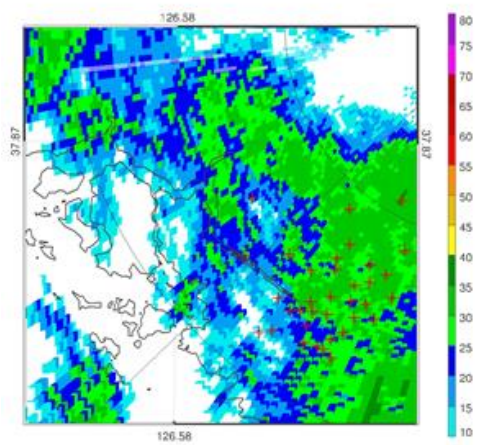

(e)

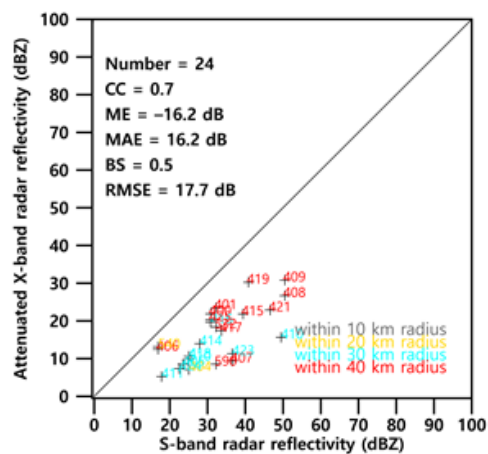

(c)

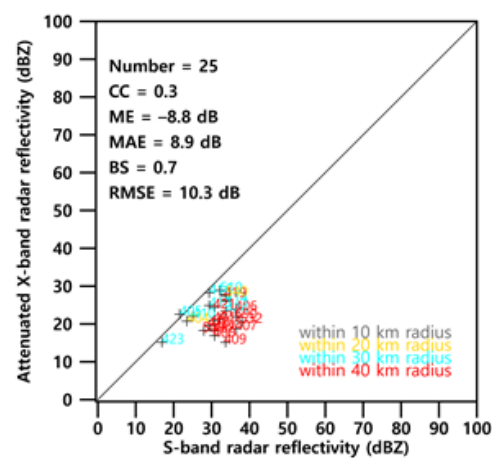

(f)

Figure 4. Plan position indicators (PPIs) of reflectivity without attenuation correction during convective rain by (a) the X-band radar, (b) the S-band radar, and (c) a comparison between the two. $(\mathbf{d}-\mathbf{f})$ are the same as $(\mathbf{a}-\mathbf{c})$, respectively, but during stratiform rain. 


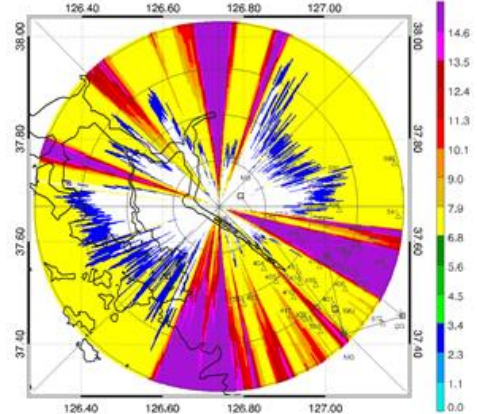

(a)

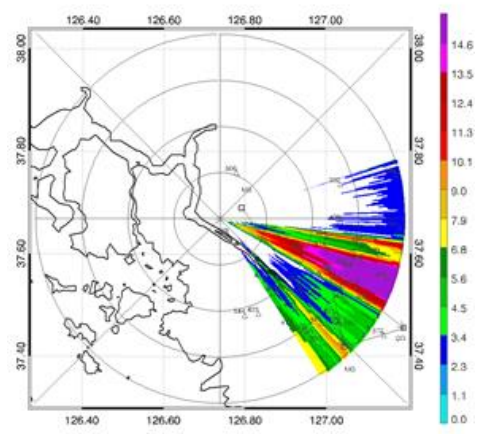

(d)

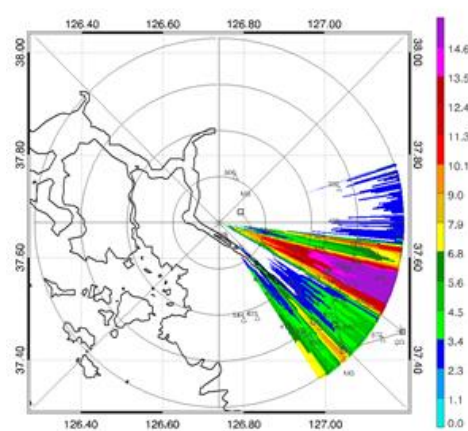

(g)

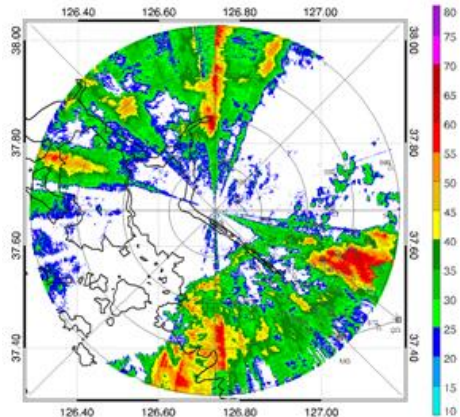

(b)

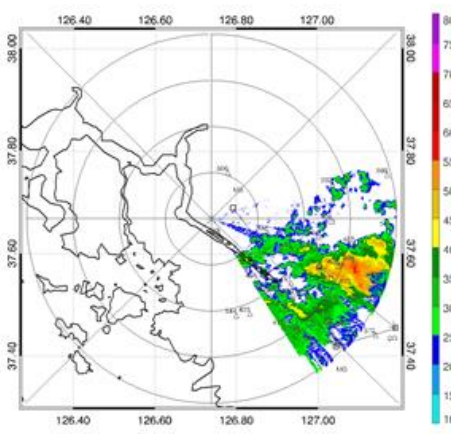

(e)

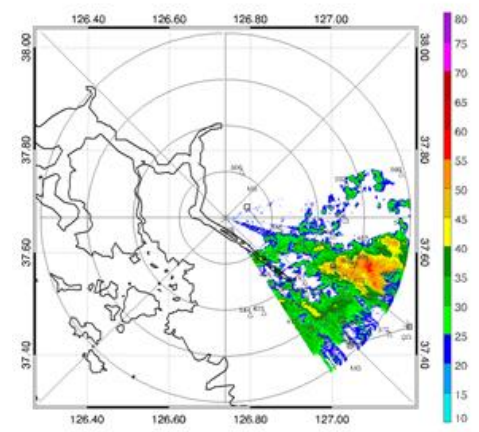

(h)

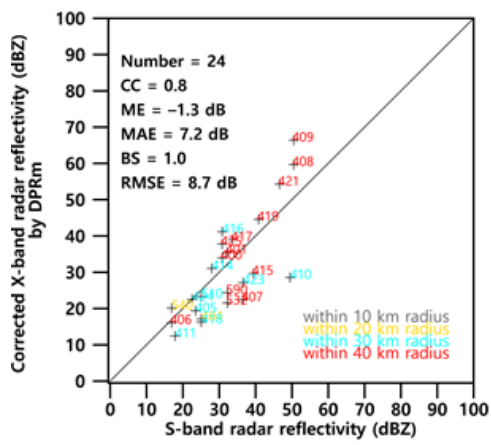

(c)

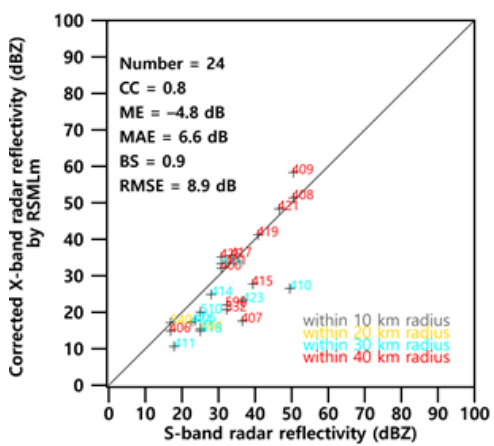

(f)

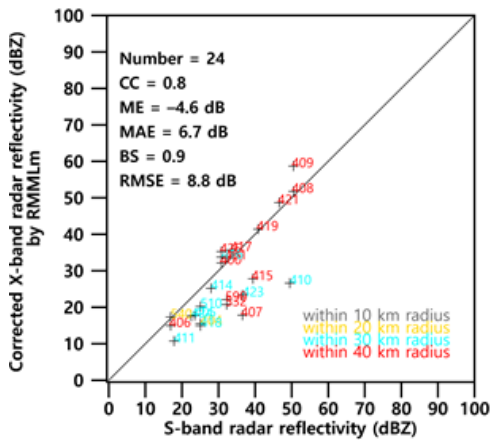

(i)

Figure 5. Radar attenuation for the convective case as estimated using the three correction methods $(\mathbf{a}, \mathbf{d}, \mathbf{g})$. Their corrected reflectivity values are shown in the middle column $(\mathbf{b}, \mathbf{e}, \mathbf{h})$, and comparisons between S-band radar reflectivity and corrected X-band radar reflectivity are presented in the right column $(\mathbf{c}, \mathbf{f}, \mathbf{i})$. The top line represents DPRm, the middle line is the RSML method, and the bottom line is the RMML method.

To further evaluate the performance of the RMMLm, corrected reflectivity with RMMLm compared to the S-band radar reflectivity is shown in Figure 5i. A comparison with the result of the attenuated $\mathrm{X}$-band radar reflectivity showed that RMMLm was effective. The ME decreased from $-16.2 \mathrm{~dB}$ to $-4.6 \mathrm{~dB}$, the MAE decreased from $16.2 \mathrm{~dB}$ to $6.7 \mathrm{~dB}$, BS increased from 0.5 to 0.9 , and RMSE decreased from $17.7 \mathrm{~dB}$ to $8.8 \mathrm{~dB}$. However, the effectiveness before and after the attenuation correction methods (RSMLm and RMMLm) were almost the same as with the convective rainfall case. The statistical scores between RSMLm and RMMLm were almost identical.

A total of 24 volumes of scan data were collected during the convective rainfall case, and 52 volumes of scan data were collected during the stratiform rainfall case by the X-band radar. The maximum correction coefficient, $\alpha$, varied over time during the convective and stratiform rainfall cases (not shown). Among the seven microwave links in the convective rainfall case, the maximum $\alpha$ was nine times greater in microwave links 3 and 5. At times, these links yielded similar values of maximum $\alpha$ 
(e.g., links 6 and 7 yielded the same correction coefficient during the first convective rainfall case) as those of the same rainfall case. In the case of the stratiform rainfall case, the maximum $\alpha$ was 21 times in the microwave link 5. Each microwave link provides a specific attenuation reference $A_{M L}$ for calculating each mean of the radar specific attenuation $\overline{A_{R}}$. Unlike RSMLm, when a microwave link misses a $A_{M L}$, the RMMLm can stably estimate the optimized coefficient and correct the attenuation of the X-band radar reflectivity. These results indicate that the advantages of RMMLm can be utilized effectively when, for example, one of the microwave links does not provide a realistic reference of attenuation because of heavy precipitation. For example, Zhang et al. [13] reported missing microwave link attenuation data because of severe attenuation from a downpour.

The height and volume of each radar gate along a microwave link differed because of variations in the distance from the radar to different parts of the microwave link [13]. Therefore, $A_{H}$ was calculated using volumes at different heights and with different sizes. In general, the radar reflectivity volume increases with distance from the microwave link to the radar. When the microwave link is located far from the radar, uncertainties can occur when estimating $\overline{A_{R}}$. The uncertainties then increase because of the spatial mismatch between the radar and microwave link. Therefore, to ensure that the method is effective, the link must not be excessively long.

Figure $6 \mathrm{~b}, \mathrm{e}, \mathrm{h}$ show the X-band radar reflectivity field at 22:00 LST on 2 May 2016, for a single scan after using each attenuation field of DPRm, RSMLm, and RMMLm (Figure 6a,d,g, respectively). The maximum corrected X-band reflectivity was approximately $33 \mathrm{dBZ}$, whereas the corresponding S-band reflectivity was approximately $38 \mathrm{dBZ}$. Although the effectiveness levels of the attenuation correction methods were mostly similar to the stratiform case, the CCs were lower and other statistical scores were superior in the convective case (Figure $6 \mathrm{c}, \mathrm{f}, \mathrm{i}$ ). The statistical scores between RSMLm and RMMLm are almost identical because the optimal $\alpha_{\text {opt }}$ determined by RSMLm and the optimal $\alpha_{\text {opt }}$ determined by RMMLm are same at this time. In the case of the stratiform rainfall, the attenuation was not large because of homogeneous and weak rainfall echoes.

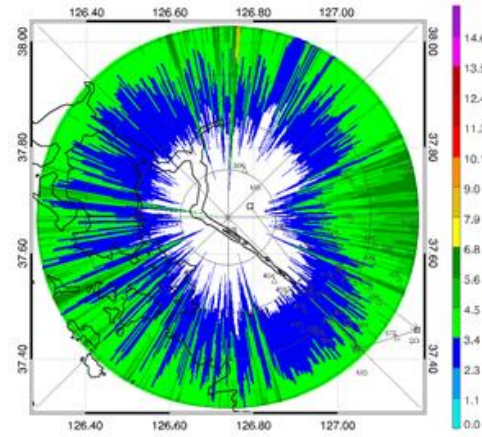

(a)

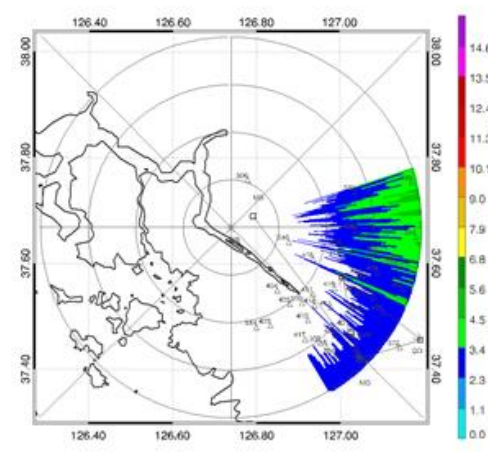

(d)

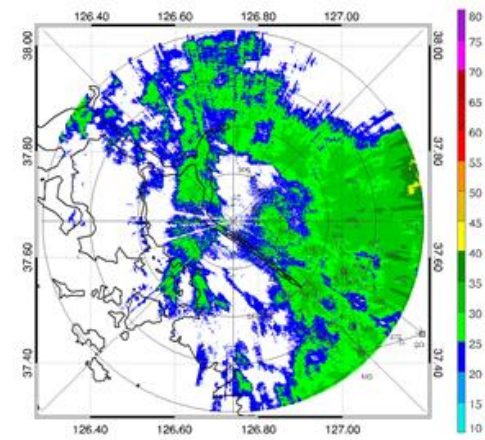

(b)

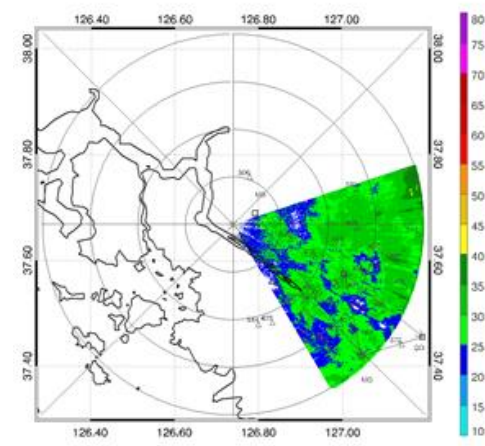

(e)

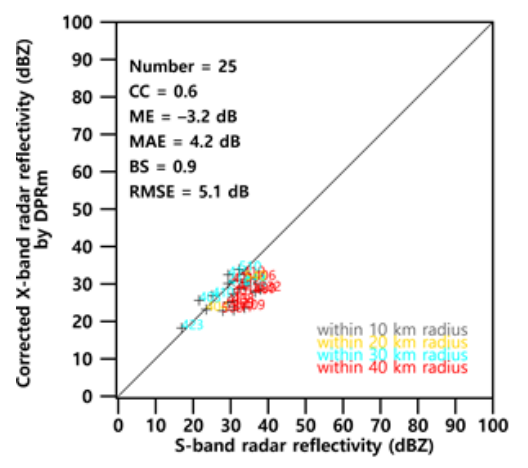

(c)

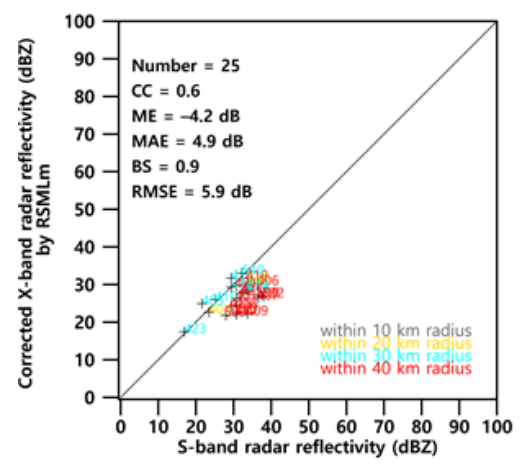

(f)

Figure 6. Cont. 


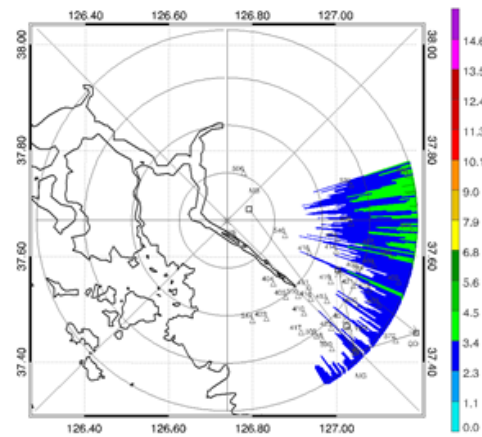

(g)

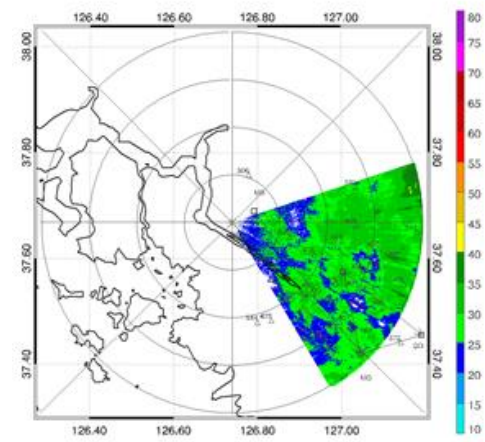

(h)

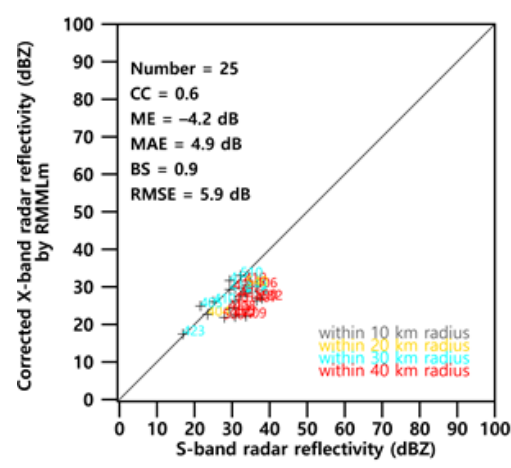

(i)

Figure 6. Same as Figure 5 but for the stratiform case.

\subsection{Attenuation Correction Using Microwave Link only}

Figure 7a shows the distribution of the SMLm attenuation at 07:00 LST on 5 July 2016. The attenuation correction coefficients are based on the relationship $A_{H}-Z_{H}$ and $a(=0.0007)$ and $b(=0.7)$ are determined. These attenuation coefficients are in the range proposed by previous studies $[10,11,28,29]$. The maximum attenuation was $1.2 \mathrm{~dB}$, which was relatively smaller than the maximum attenuation calculated using the other attenuation corrections. This was because the MB link was used, and it had the longest link length $(37.4 \mathrm{~km})$ and a lower frequency than the others. In addition, the radials of the radar and microwave link were not parallel. Krämer et al. [10] found that the SMLm remained stable for a path-integrated attenuation below $15 \mathrm{~dB}$. After attenuation correction, the $X$-band radar reflectivity increased weakly within $60-160^{\circ}$ and evidently within $315-45^{\circ}$ (Figure $7 \mathrm{~b}$ ). The textures on the far range of the X-band radar reflectivity after SMLm were different from those with the S-band radar reflectivity. The ME, MAE, and RMSE decreased, whereas the BS increased (Figure 7c). However, the effectiveness of the SMLm was lower than those of DPRm, RSMLm, and RMMLm with respect to this case.

The MMLm attenuation field was calculated using the time-varying optimal attenuation correction coefficient, $a$, which was determined as the maximum value among each correction coefficient $a$ from the golden-section search method with each $A_{R E F}$ and $\overline{A_{R}}$ and $b$ was set to 0.9 (Figure $7 \mathrm{~d}$ ). The maximum attenuation was $14 \mathrm{~dB}$, the corrected X-band radar reflectivity increased within $60-160^{\circ}$ and was clearly increased within $315-45^{\circ}$ (Figure 7e), and there were considerable changes in the textures of the reflectivity. Specifically, the weak reflectivity on the far range $(30-40 \mathrm{~km})$ of the X-band radar increased from $10 \mathrm{dBZ}$ to $30 \mathrm{dBZ}$, compared with the uncorrected X-band radar reflectivity. The echoes within $50-70^{\circ}$ on the far range of the X-band radar were more intense after MMLm than after SMLm, and they were closer to the S-band radar reflectivity. To further evaluate the performance of the MMLm, the corrected reflectivity with MMLm was calculated against the S-band radar reflectivity, and the results are presented in Figure $7 \mathrm{f}$. Compared with the result of attenuated X-band radar reflectivity, the effectiveness of using MMLm is evident. The ME decreased from $-16.2 \mathrm{~dB}$ to $-3.3 \mathrm{~dB}$, the MAE decreased from $16.2 \mathrm{~dB}$ to $6.7 \mathrm{~dB}$, BS increased from 0.5 to 0.9 , and the RMSE decreased from $17.7 \mathrm{~dB}$ to $8.2 \mathrm{~dB}$ (Figure 7f).

Compared with the result of SMLm, the ME decreased from $-10.6 \mathrm{~dB}$ to $-3.3 \mathrm{~dB}$, the MAE decreased from $10.6 \mathrm{~dB}$ to $6.7 \mathrm{~dB}$, BS increased from 0.7 to 0.9 , and RMSE decreased from $12.6 \mathrm{~dB}$ to $8.2 \mathrm{~dB}$. The advantages of MMLm effectively reduced the instability problems of the SMLm; this occurred with respect to the use of the golden-section search method and the adjacent multiple microwave links. 


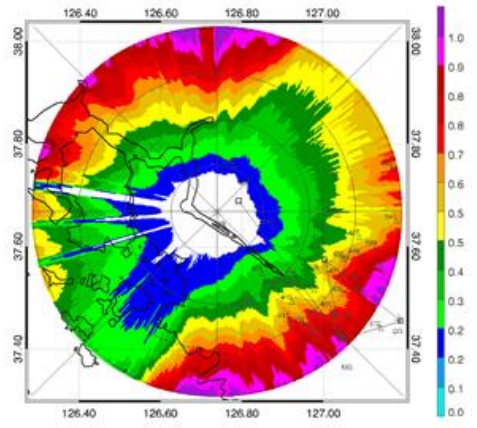

(a)

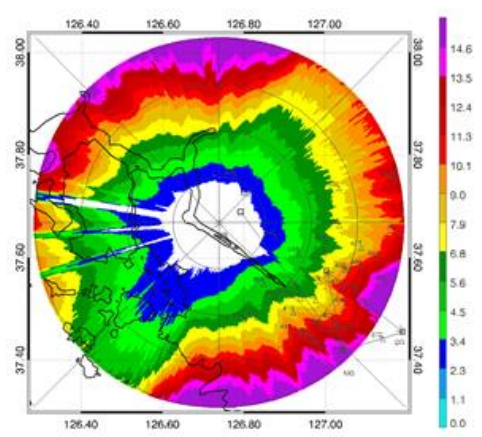

(d)

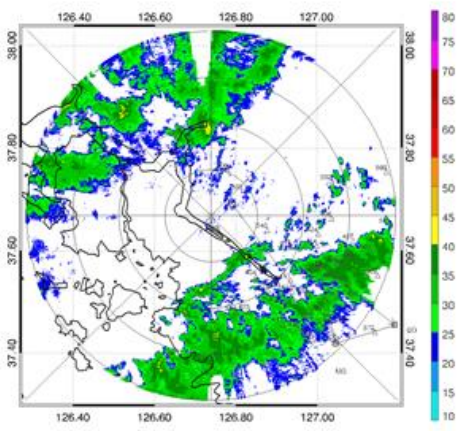

(b)

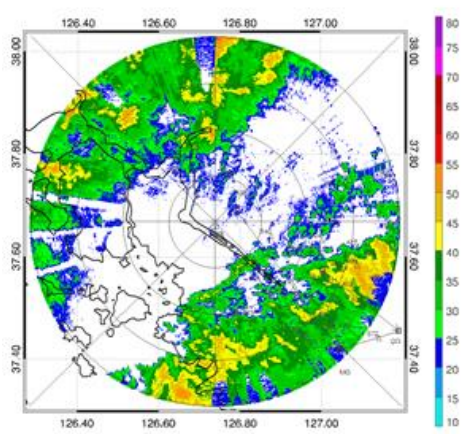

(e)

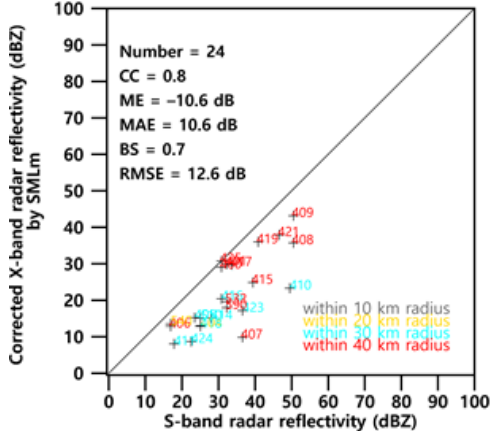

(c)

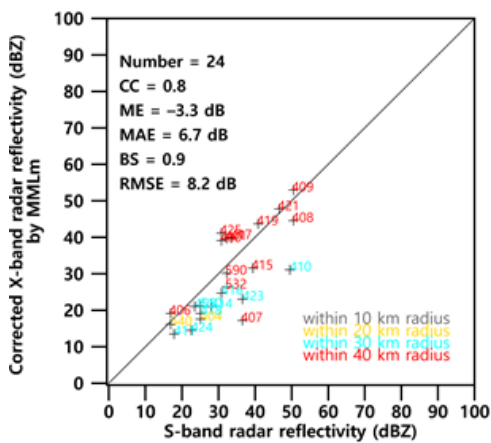

(f)

Figure 7. Radar attenuation estimated for the convective case using the two correction methods (a,d). Their corrected reflectivity is shown in the middle row $(\mathbf{b}, \mathbf{e})$, and comparisons between S-band radar reflectivity and corrected X-band radar reflectivity are presented in the right row $(\mathbf{c}, \mathbf{f})$. The top line represents SMLm, and the bottom line is the MMLm.

The distribution of $A_{H}$ at 22:00 LST on 2 May 2016, for a single scan after using SMLm shows that the results of MMLm are lower than for the convective rainfall case (Figure 8a,d). Following SMLm, the X-band radar reflectivity slightly increased, and minimal changes were observed in the reflectivity textures (Figure $8 \mathrm{~b}, \mathrm{e}$ ). In addition, the statistical scores were based on, e.g., ME, MAE, and RMSE decreased and BS increased. ME decreased from $-8.8 \mathrm{~dB}$ to $-6.1 \mathrm{~dB}$, MAE decreased from $8.9 \mathrm{~dB}$ to $4.9 \mathrm{~dB}$, BS increased from 0.7 to 0.9 , and RMSE decreased from $10.3 \mathrm{~dB}$ to $5.9 \mathrm{~dB}$ (Figure $8 \mathrm{c}$ ). These results show that the attenuation-corrected reflectivity in the stratiform rainfall case seemed to be relatively more consistent for S-band radar reflectivity than the corrected reflectivity in the convective rainfall case because stratiform rainfall has more homogeneous and weaker rainfall echoes.

Figure $8 \mathrm{f}$ shows the performance of the corrected reflectivity using the MMLm against that of the $\mathrm{S}$-band radar reflectivity. The results of the corrected reflectivity are more consistent with the S-band radar reflectivity than the attenuated X-band radar reflectivity. $\mathrm{ME}$ decreased from $-8.8 \mathrm{~dB}$ to $-0.1 \mathrm{~dB}$, MAE decreased from $8.9 \mathrm{~dB}$ to $3.1 \mathrm{~dB}$, BS increased from 0.7 to 1.0, and RMSE decreased from $10.3 \mathrm{~dB}$ to $3.7 \mathrm{~dB}$. In addition, the MMLm results are superior to the SMLm results: ME decreased from $-6.1 \mathrm{~dB}$ to $-0.1 \mathrm{~dB}$, MAE decreased from $6.4 \mathrm{~dB}$ to $3.1 \mathrm{~dB}$, BS increased from 0.8 to 1.0, and RMSE decreased from $7.7 \mathrm{~dB}$ to $3.7 \mathrm{~dB}$. MMLm reduced the instability problems of the SMLm by using the golden-section search method and adjacent multiple microwave links when microwave link attenuation data were missing because of severe attenuation from downpours [13].

Figure 9a shows box-whisker plots for $a$, which was determined by the MMLm during the convective rainfall case. From 10:21 to 14:50 LST on 5 July 2016, 24 volume scan data were collected by the X-band radar. Furthermore, Figure $9 \mathrm{~b}$ shows $a$ determined by the MMLm during the stratiform rainfall case. From 19:21 LST on 2 May 2016, to 08:50 LST on 3 May 2016, 52 volumes of scan data were collected by the X-band radar. Each individual optimal $a$ was determined using the MMLm within 0.001-0.014. The range of correction coefficient for microwave links 6 and 7 were higher than those 
of other microwave links. This is because links 6 and 7 have the shortest link path, and the distance between antenna (transmitter and receiver) and KICT radar is long. Leijnse et al. [34] stated that if most of the variation in rainfall occurs within a link, then the relation between specific attenuation and rainfall rate will have to be close to linear. The typical spatial scales are relatively distributed in ranges

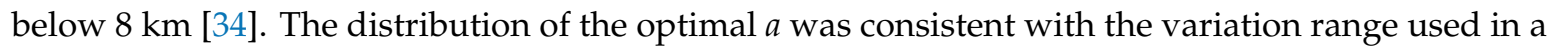
previous study [5].

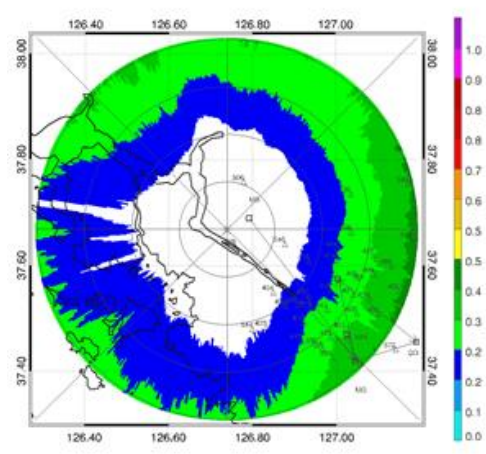

(a)

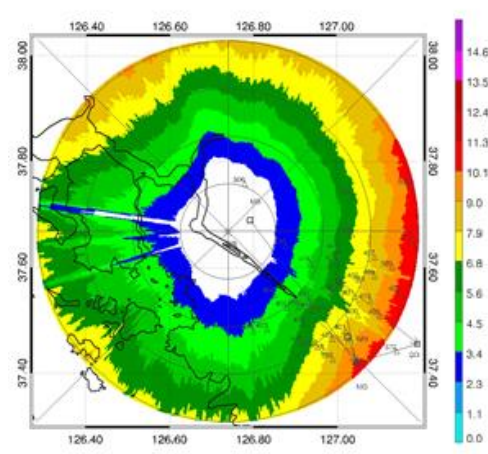

(d)

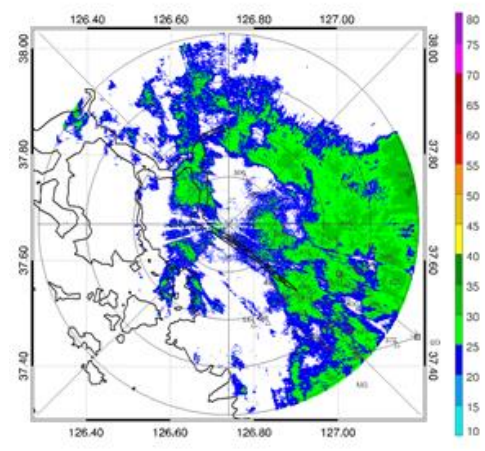

(b)

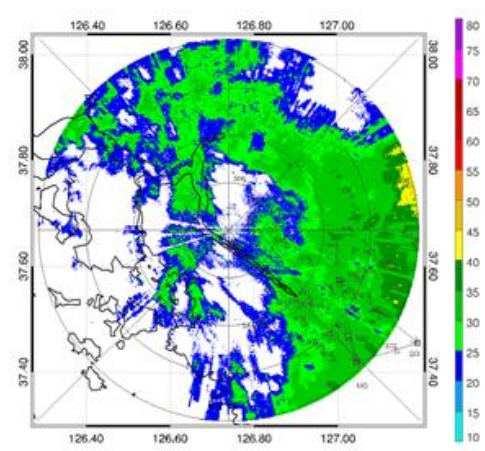

(e)

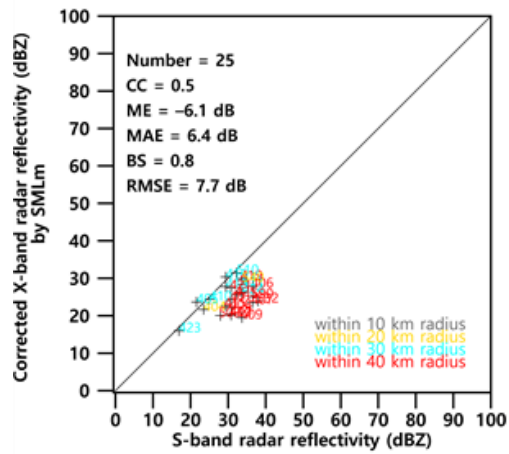

(c)

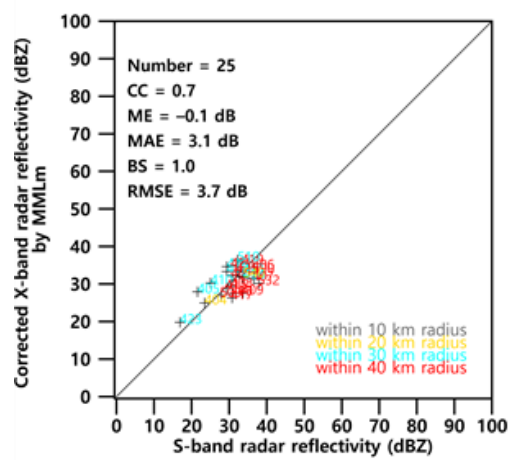

(f)

Figure 8. Same as Figure 7 but for the stratiform case.

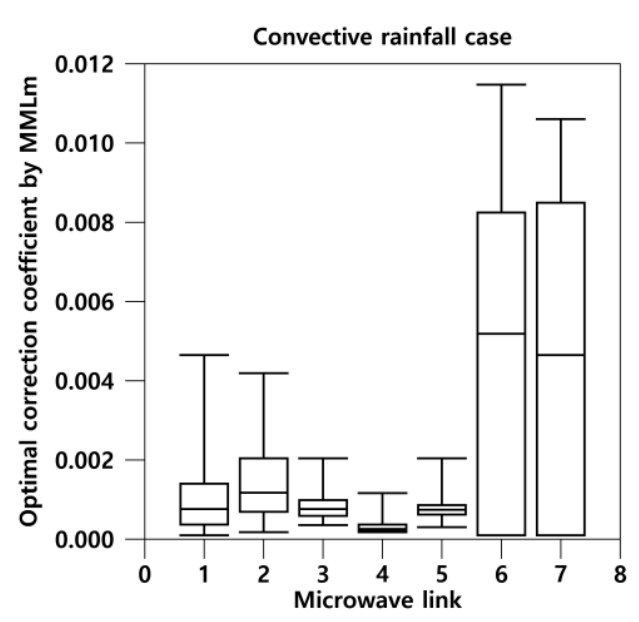

(a)

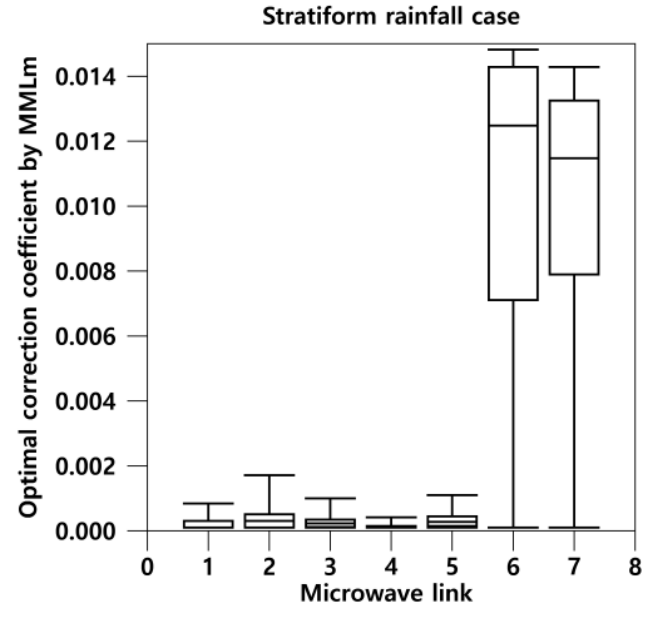

(b)

Figure 9. Box-whisker plots of time-varying optimized attenuation correction coefficients, $a$, with each individual microwave link determined by MMLm during (a) the convective rainfall case and (b) the stratiform rainfall case. 


\section{Discussion}

To further assess the performance of each correction method, the attenuation corrected X-band reflectivity values obtained via DPRm, RSMLm, RMMLm, SMLm, and MMLm were compared against the S-band radar reflectivity values, and the results are shown in Figure 10. Reflectivity values from 10:21 to 14:50 LST on 5 July 2016, at 10 min intervals (720 radar scans in total) were selected as subjects for a comparison, as shown in Figure 10a-f. The X-band radar reflectivity values corrected through MMLm are highly consistent with those of the S-band radar reflectivity: The ME, MAE, and RMSE decreased and BS increased relative to the attenuated X-band radar reflectivity and corrected X-band radar reflectivity; therefore, the statistical values were evidently improved. Reflectivity values recorded during 19:21 LST on 2 May 2016 to 08:50 LST on 3 May 2016, at 10 min intervals (1240 radar scans in total) were investigated to conduct further comparison (Figure 9a-i). Unlike in the convective rainfall case, no large differences were found in the observed effectiveness before and after attenuation. This is because stratiform rainfall exhibits relatively more homogeneous and weaker rainfall echoes.

Moreover, the differences in the performance between the correction methods were not large; however, errors were observed to commonly occur in the results. Even though we converted the S-band radar reflectivity to the intrinsic reflectivity in the X-band using the empirical conversion method [15], one reason for these errors may be the accuracy of the empirical conversion method. This can also be regarded as another reason that relates to the radar beam heights (RBHs) of the two different radars. Despite changing the elevation angles of the S-band radar from $0^{\circ}$ to $1.7^{\circ}$ to identify the smallest differences between RBHs (Table 4), differences between the RBHs persisted because of the differences in the impact of antenna elevations, distances between the antennae and RBHs, and the earth's curvature. Results showed that the minimum, maximum, median, and average RBH difference between the X-band and S-band radars was $0,1.0,0.1$, and $0.2 \mathrm{~km}$, respectively. The radar reflectivity volume increased in accordance with the distance from the microwave link to the radar and may have caused uncertainties in the estimation of $\overline{A_{R}}$ when the microwave link was far from the weather radar. Furthermore, the uncertainties were bound to increase because of the spatial mismatch between the radar and the microwave link.

With respect to the stratiform rainfall case, the corrected $X$-band radar reflectivity of all five attenuation correction methods were commonly greater than the S-band radar reflectivity (Figure 10a-i). One reason for this was the bright band phenomenon, which appeared from 16:00 LST on 2 May 2016 to 23:50 LST on 2 May 2016. A bright band is defined as a horizontal layer of strong radar reflectivity produced during the transition of the melting of accumulated precipitation to the rain state [3]. Bright band contamination could contribute to rainfall estimation errors from weather radar systems [24].

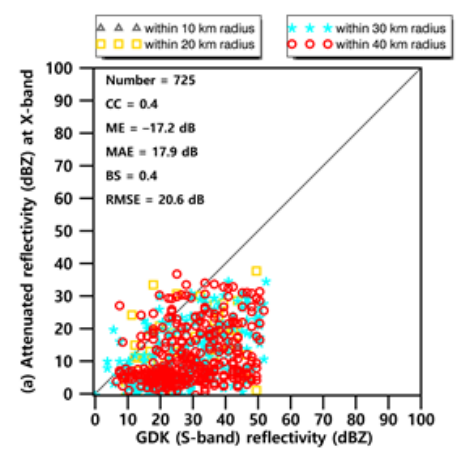

(a)

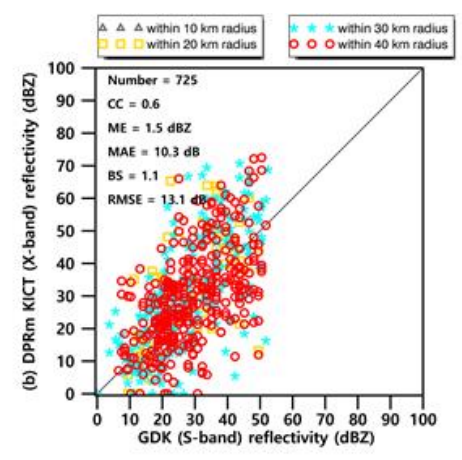

(b)

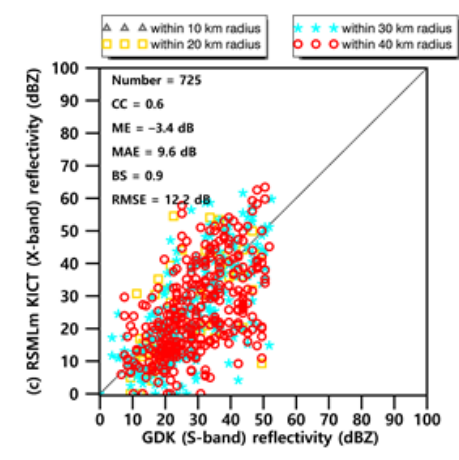

(c)

Figure 10. Cont. 


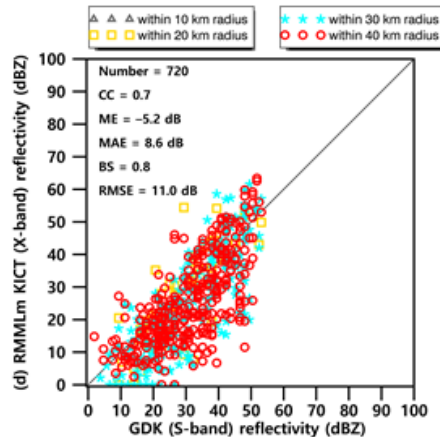

(d)

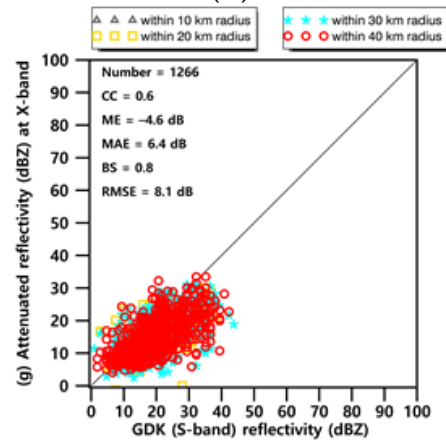

$(\mathrm{g})$

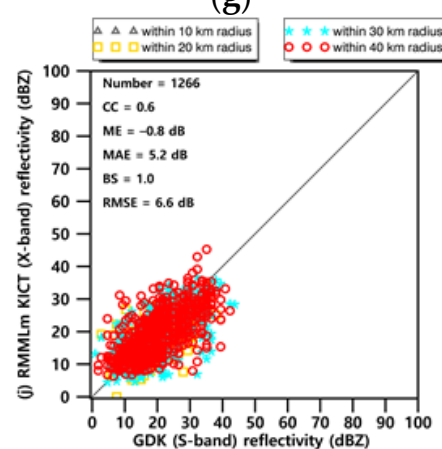

(j)

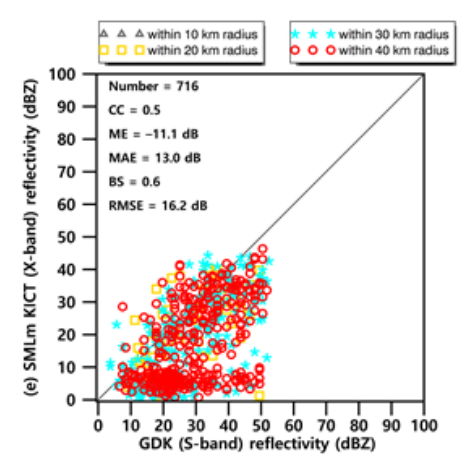

(e)

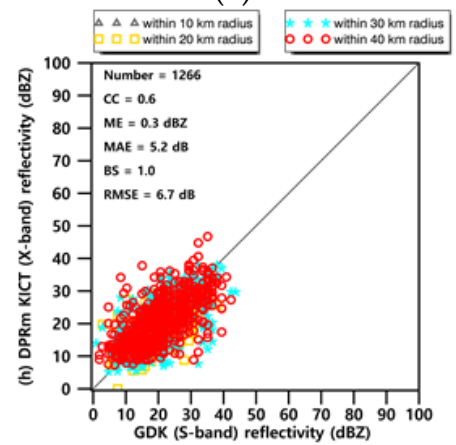

(h)

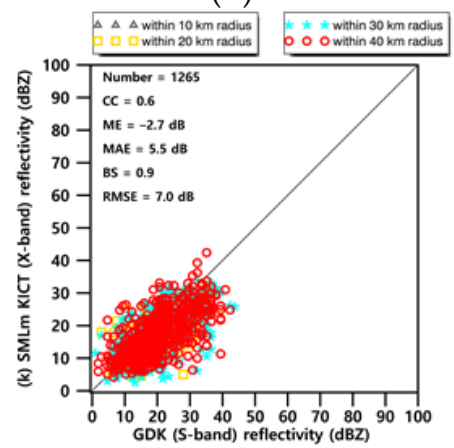

$(\mathbf{k})$

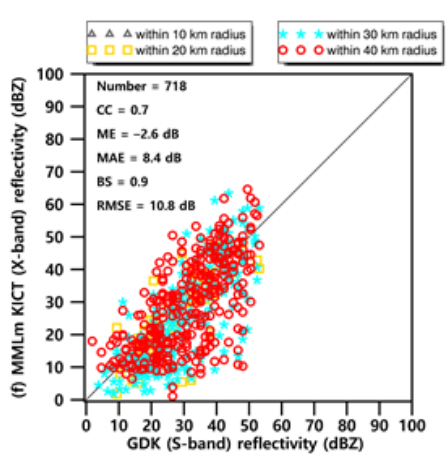

(f)

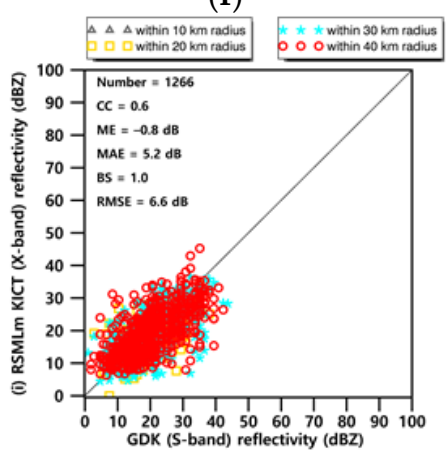

(i)

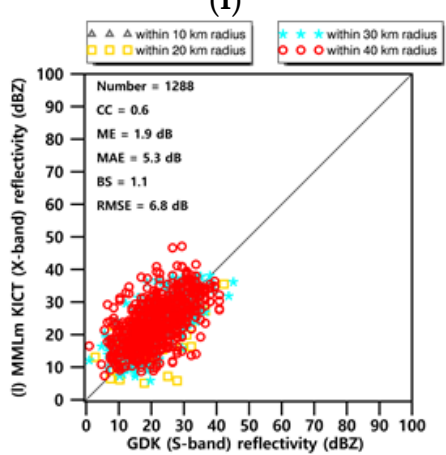

(1)

Figure 10. Scatter plots of the X-band radar reflectivity (a) before attenuation correction and after (b) DPRm, (c) SMLm, (d) RSMLm, (e) RMMLm, and (f) MMLm against reflectivity retrieved by the S-band radar over the 36 AWS sites during the convective rainfall case. Scatter plots of X-band radar reflectivity (g) before attenuation correction and after (h) DPRm, (i) SMLm, (j) RSMLm, (k) RMMLm, and (1) MMLm against reflectivity retrieved by the S-band radar over 36 AWS sites during the stratiform rainfall case.

Table 4. Radar beam heights (RBH) over the 36 AWS sites.

\begin{tabular}{ccccccccc}
\hline $\begin{array}{c}\text { AWS } \\
\text { Site }\end{array}$ & $\begin{array}{c}\text { KICT } \\
\text { RBH (km) }\end{array}$ & $\begin{array}{c}\text { GDK } \\
\text { RBH (km) } \\
\text { /Elevation }\left(^{\circ}\right)\end{array}$ & $\begin{array}{c}\text { AWS } \\
\text { Site }\end{array}$ & $\begin{array}{c}\text { KICT } \\
\text { RBH (km) }\end{array}$ & $\begin{array}{c}\text { GDK } \\
\text { RBH (km) } \\
\text { /Elevation }\left(^{\circ}\right)\end{array}$ & $\begin{array}{c}\text { AWS } \\
\text { Site }\end{array}$ & $\begin{array}{c}\text { KICT } \\
\text { RBH (km) }\end{array}$ & $\begin{array}{c}\text { GDK } \\
\text { RBH (km) } \\
\text { /Elevation }\left({ }^{\circ}\right)\end{array}$ \\
\hline 116 & 2.8 & $2.7 / 1.0$ & 411 & 2.0 & $2.2 / 0.6$ & 506 & 0.9 & $1.3 / 0.0$ \\
\hline 400 & 2.9 & $2.6 / 1.0$ & 413 & 2.9 & $2.6 / 1.0$ & 509 & 2.6 & $2.7 / 1.0$ \\
\hline 401 & 2.9 & $2.8 / 1.0$ & 414 & 2.1 & $2.0 / 0.6$ & 510 & 1.9 & $1.8 / 0.3$ \\
\hline 402 & 3.4 & $3.3 / 1.7$ & 415 & 2.4 & $2.2 / 0.6$ & 532 & 2.3 & $2.1 / 1.0$ \\
\hline 403 & 3.2 & $3.5 / 1.7$ & 416 & 1.6 & $1.5 / 0.2$ & 540 & 1.2 & $1.3 / 0.0$ \\
\hline
\end{tabular}


Table 4. Cont.

\begin{tabular}{ccccccccc}
\hline $\begin{array}{c}\text { AWS } \\
\text { Site }\end{array}$ & $\begin{array}{c}\text { KICT } \\
\text { RBH (km) }\end{array}$ & $\begin{array}{c}\text { GDK } \\
\text { RBH (km) } \\
\text { /Elevation }\left(^{\circ}\right)\end{array}$ & $\begin{array}{c}\text { AWS } \\
\text { Site }\end{array}$ & $\begin{array}{c}\text { KICT } \\
\text { RBH (km) }\end{array}$ & $\begin{array}{c}\text { GDK } \\
\mathbf{R B H}(\mathbf{k m}) \\
\text { /Elevation }\left(^{\circ}\right)\end{array}$ & $\begin{array}{c}\text { AWS } \\
\text { Site }\end{array}$ & $\begin{array}{c}\text { KICT } \\
\text { RBH (km) }\end{array}$ & $\begin{array}{c}\text { GDK } \\
\mathbf{R B H}(\mathbf{k m}) \\
\text { /Elevation }\left({ }^{\circ}\right)\end{array}$ \\
\hline 404 & 1.5 & $1.4 / 0.0$ & 417 & 2.4 & $2.3 / 0.6$ & 541 & 3.3 & $2.9 / 1.7$ \\
\hline 405 & 1.9 & $1.9 / 0.3$ & 418 & 2.2 & $2.3 / 0.6$ & 544 & 1.9 & $2.0 / 0.3$ \\
\hline 406 & 2.2 & $2.3 / 1.0$ & 419 & 2.2 & $2.1 / 0.6$ & 569 & 3.2 & $3.1 / 1.7$ \\
\hline 407 & 2.8 & $3.1 / 1.7$ & 421 & 2.7 & $2.6 / 1.0$ & 572 & 3.5 & $3.7 / 1.7$ \\
\hline 408 & 2.6 & $2.5 / 1.0$ & 423 & 2.0 & $1.9 / 0.3$ & 589 & 0.3 & $1.4 / 0.0$ \\
\hline 409 & 2.9 & $3.2 / 1.7$ & 424 & 1.9 & $1.9 / 0.6$ & 590 & 3.2 & $2.9 / 1.0$ \\
\hline 410 & 2.3 & $2.3 / 0.6$ & 425 & 2.9 & $2.8 / 1.0$ & 599 & 3.4 & $2.4 / 1.7$ \\
\hline
\end{tabular}

Figure 11a shows a Skew T-Log P diagram provided by KMA. The bright band peak ( $37.9 \mathrm{dBZ})$ occurred at a height of around $3.4 \mathrm{~km}$ (Figure 11b) at 17:40 LST on 2 May 2016. The freezing level was also at around $3.4 \mathrm{~km}$ at the time (according to an upper-air observatory in Osan located nearest to the X-band radar site), and weak reflectivity was prevalent (less than around $30 \mathrm{dBZ}$ ) (Figure 11c,d). The bright band appeared from 15:00 LST on 2 May 2016 to 23:50 LST on 2 May 2016. However, we confirmed that bright band contamination prevented the overestimation of the corrected reflectivity (Figure 10h-l) because most RBHs of the X-band and the S-band were below $3.4 \mathrm{~km}$ (Table 4 ). Cunningham et al. used reflectivity at an elevation angle of 1.6 and an area between $20 \mathrm{~km}$ and $80 \mathrm{~km}$ from the radar's center was used to avoid bright band contamination and ground clutter.

Figure 12 shows the performance of the corrected reflectivity with the MMLm using different values of the optimal correction coefficient $a$ (e.g., maximum, minimum, median, and mean) against that of S-band radar reflectivity. The results of the corrected reflectivity with the MMLm using the mean correction coefficient $a$ are more consistent than the attenuated X-band radar reflectivity with that of the S-band radar reflectivity. A comparison between the corrected reflectivity via MMLm, whereby max correction coefficient $a$ was applied and one whereby mean correction coefficient $a$ was applied, showed that the ME decreased from $6.3 \mathrm{~dB}$ to $1.9 \mathrm{~dB}$, the MAE decreased from $7.9 \mathrm{~dB}$ to $5.3 \mathrm{~dB}$, BS decreased from 1.3 to 1.1, and RMSE decreased from $9.7 \mathrm{~dB}$ to $6.8 \mathrm{~dB}$. 


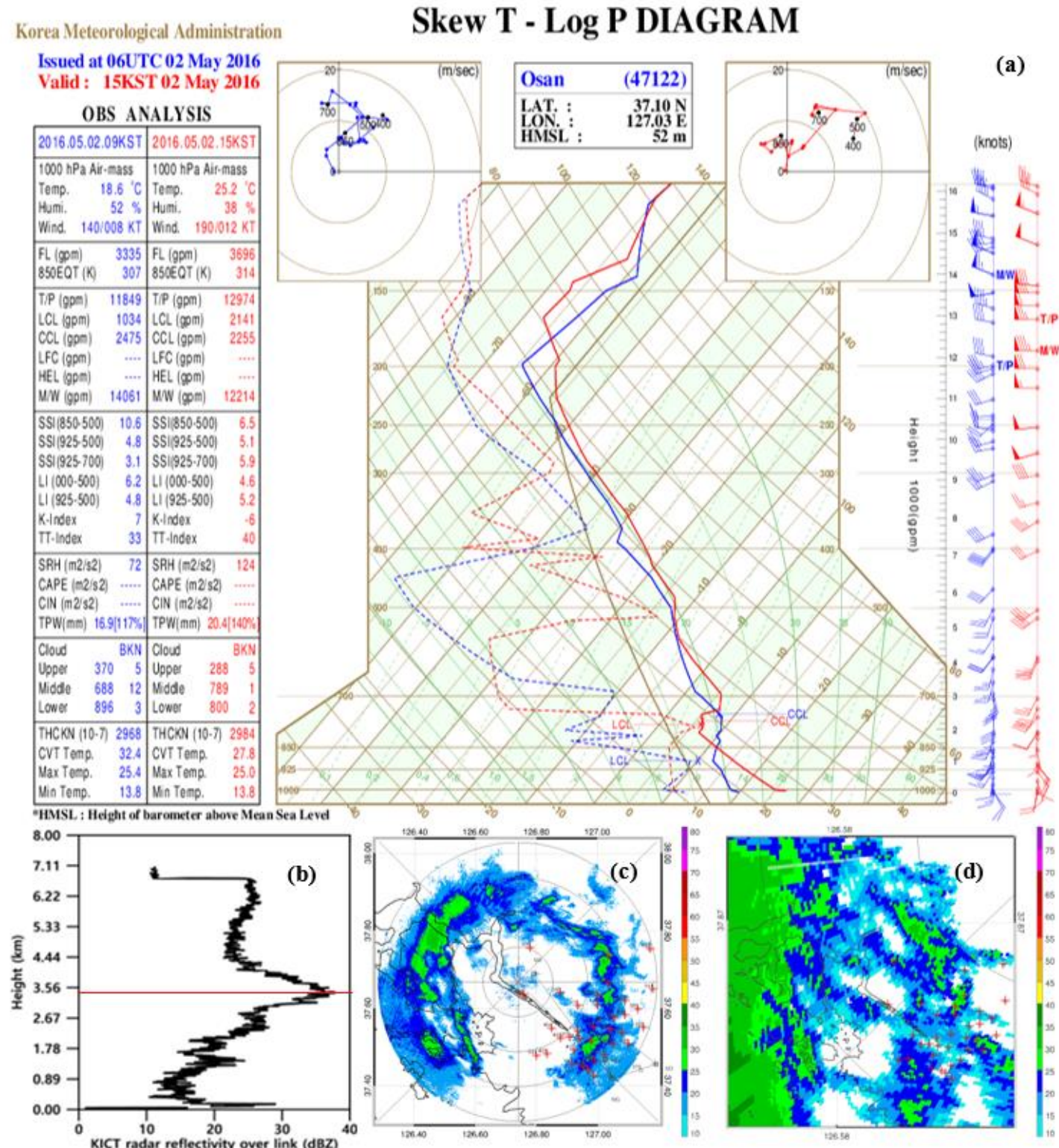

Figure 11. (a) Upper-air sounding data at Osan station. The blue and red solid lines represent temperature and dew-point temperature, respectively, and the areas shaded with red and blue colors represent the convective available potential energy and convective inhibition, respectively, (b) profile of X-band radar reflectivity at azimuth $134^{\circ}$ at 17:31 LST on 2 May 2016. Spatial distributions of the (c) $\mathrm{X}$-band and (d) the S-band radar reflectivity. 


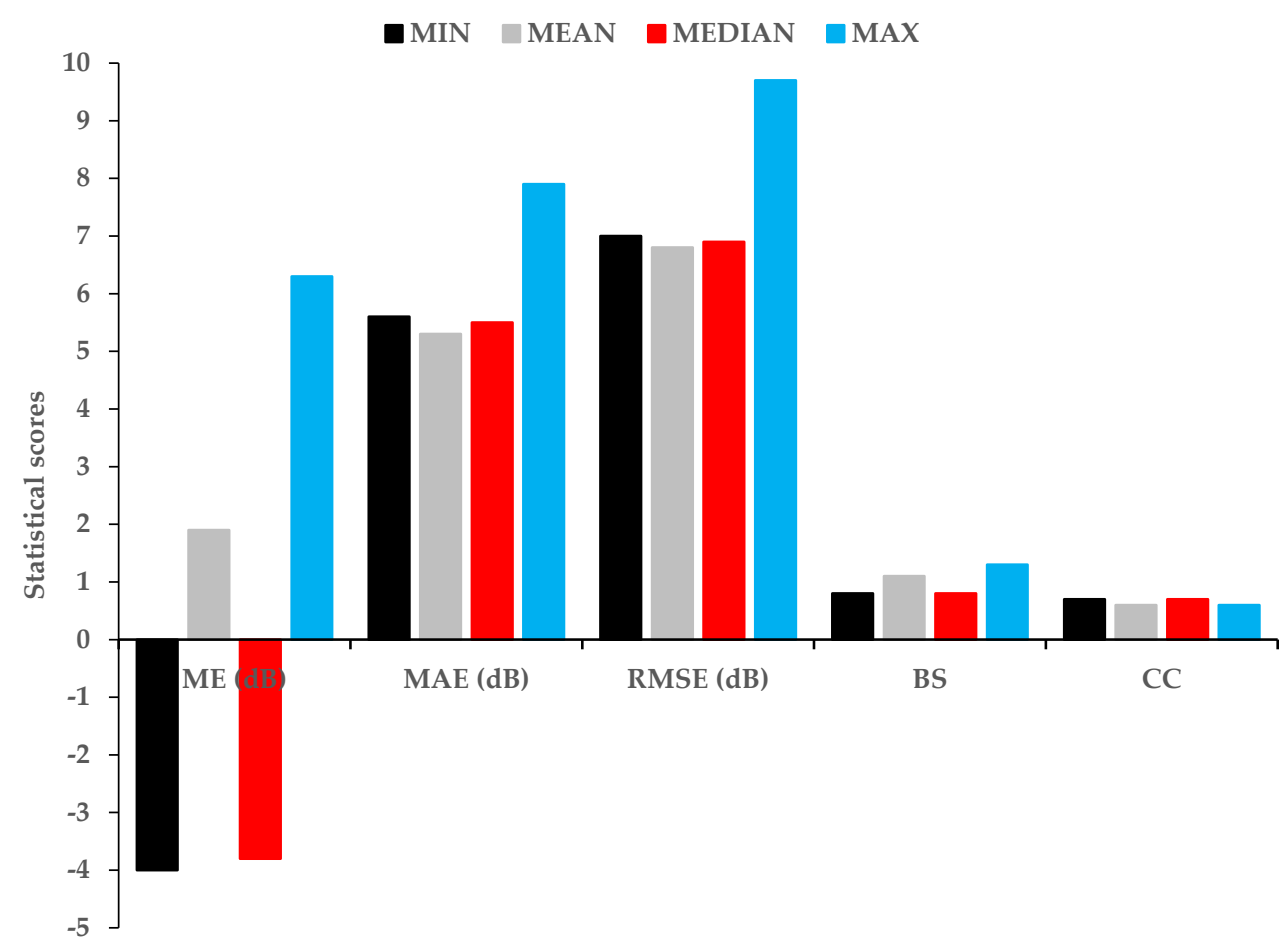

Figure 12. Bar graph showing the performance of corrected reflectivity with the MMLm using different optimal correction coefficient $a$ for the stratiform rainfall case.

\section{Conclusions}

Attenuation correction of the X-band radar is one of the most important factors in hydrometeorological studies. This is because attenuation is significantly greater in the X-band than in the C or S-bands. In this study, we compared the use of four correction techniques and proposed a technique based on the reference attenuation from adjacent multiple microwave links, namely, the multiple microwave links method (MMLm). The required number of microwave links and their locations were optimized. The attenuation of the X-band radar reflectivity was corrected forward-iteratively at each microwave link, and the correction coefficients were statistically analyzed to reduce uncertainties. Furthermore, the correction coefficients $a$ and $\alpha$ were optimized and stabilized. The estimated correction coefficients show that the variation ranges of optimized $a$ and $\alpha$ were overall consistent with those proposed in previous studies. This method effectively reduces instability associated with problems occurring when estimating $a$ and $\alpha$ and broadens the application scope of ground-based microwave links. The attenuation-correction method can account for spatiotemporal differentiation depending on rainfall and recover the physical structure of the rainfall.

The algorithms of the various methods were evaluated using two rainfall cases (convective and stratiform rainfall) and validated by comparing the corrected reflectivity of the X-band radar with the suitable controlled reflectivity of the S-band radar. Compared with the results of the attenuated X-band radar reflectivity, the results of the MMLm are as effective as those of the conventional method based on the specific differential phase of dual-polarimetric radar.

Rainfall observation technology using microwave links can substantially reduce rainfall observation costs by utilizing the infrastructure operated with respect to global broadcasting and telecommunication, and lower rainfall levels over areas spanning several kilometers at a height of several tens of meters above the ground can be identified. This technology can be used to fill gaps relating to data obtained from rain gauges and radar. It can also be used economically in developing countries where rainfall observation equipment is scarce. Thus, the MMLm can be applied with arbitrary oriented microwave links and can contribute to the estimation of quantitative rainfall in developing countries where dual-polarization weather radar is not operational, thereby increasing 
microwave link networks. In future research studies, further analyses of the effectiveness of MMLm should be conducted through more observation cases and estimation of the rainfall rate using the corrected reflectivity.

Author Contributions: Conceptualization, M.-S.K.; methodology, M.-S.K.; formal analysis, M.-S.K. and B.H.K.; validation, M.-S.K.; investigation, M.-S.K. and B.H.K.; writing-original draft preparation, M.-S.K. and B.H.K.; writing-review and editing, M.-S.K. and B.H.K.; supervision, B.H.K.; funding acquisition, B.H.K. All authors have read and agreed to the published version of the manuscript.

Acknowledgments: We would like to thank the editor and the three anonymous reviewers for their comments, which helped in the substantial improvement of this manuscript. We thank the Korea Meteorological Administration and Korea Telecom for the dataset. This work was funded by the Korea Meteorological Administration Research and Development Program under Grant KMI 2019-00510.

Conflicts of Interest: The authors have no conflict of interest to declare.

\section{References}

1. Barthes, L.; Mallet, C. Rainfall measurement from the opportunistic use of an Earth-space link in the Ku band. Atmos. Meas. Tech. 2013, 6, 2181-2193. [CrossRef]

2. Ojo, J.S.; Ajewole, M.O.; Emiliani, L.D. One-minute rain-rate contour maps for microwave-communication-system planning in a tropical country: Nigeria. IEEE Antennas Propag. Mag. 2009, 51, 82-89. [CrossRef]

3. Olurotimi, E.; Sokoya, O.; Ojo, J.; Owolawi, P.A. Observation of bright-band height data from TRMM-PR for satellite communication in South Africa. J. Atmos. Sol.-Terr. Phys. 2017, 160, 24-33. [CrossRef]

4. Atlas, D.; Banks, H.C. The interpretation of microwave reflections from rainfall. J. Meteorol. 1951, 8, $271-282$. [CrossRef]

5. Park, S.; Bringi, V.; Chandrasekar, V.; Maki, M.; Iwanami, K. Correction of radar reflectivity and differential reflectivity for rain attenuation at $\mathrm{X}$ band. Part I: Theoretical and empirical basis. J. Atmos. Ocean. Technol. 2005, 22, 1621-1632. [CrossRef]

6. Testud, J.; Le Bouar, E.; Obligis, E.; Ali-Mehenni, M. The rain profiling algorithm applied to polarimetric weather radar. J. Atmos. Ocean. Technol. 2000, 17, 332-356. [CrossRef]

7. Bringi, V.; Keenan, T.; Chandrasekar, V. Correcting C-band radar reflectivity and differential reflectivity data for rain attenuation: A self-consistent method with constraints. IEEE Trans. Geosci. Remote. Sens. 2001, 39, 1906-1915. [CrossRef]

8. Kim, D.-S.; Maki, M.; Lee, D.-I. Correction of X-band radar reflectivity and differential reflectivity for rain attenuation using differential phase. Atmos. Res. 2008, 90, 1-9. [CrossRef]

9. Kim, M.-S.; Kim, M.-S. Rainfall detection and rainfall rate estimation using microwave attenuation. Atmosphere 2018, 9, 287. [CrossRef]

10. Kramer, S.; Verworn, H.-R.; Redder, A. Improvement of X-band radar rainfall estimates using a microwave link. Atmos. Res. 2005, 77, 278-299. [CrossRef]

11. Rahimi, A.R.; Holt, A.R.; Upton, G.J.G.; Kramer, S.; Redder, A.; Verworn, H.-R. Attenuation calibration of an x-band weather radar using a microwave link. J. Atmos. Ocean. Technol. 2006, 23, 395-405. [CrossRef]

12. Trömel, S.; Ziegert, M.; Ryzhkov, A.V.; Chwala, C.; Simmer, C. Using microwave backhaul links to optimize the performance of algorithms for rainfall estimation and attenuation correction. J. Atmos. Ocean. Technol. 2014, 31, 1748-1760. [CrossRef]

13. Zhang, P.; Liu, X.; Li, Z.; Zhou, Z.; Song, K.; Yang, P. Attenuation correction of weather radar reflectivity with arbitrary oriented microwave link. Adv. Meteorol. 2017, 2017, 1-17. [CrossRef]

14. Yoon, J.; Joo, J.; Yoo, C.; Hwang, S.; Lim, S. On quality of radar rainfall with respect to temporal and spatial resolution for application to urban areas. Meteorol. Appl. 2016, 24, 19-30. [CrossRef]

15. Cha, J.; Han, H.; Park, J. Current state and future plan of quality control and quantitative precipitation estimation for KMA weather radar data. Mag. IEEK 2013, 40, 129-136.

16. Baik, J.; Choi, M. Spatio-temporal variability of remotely sensed precipitation data from COMS and TRMM: Case study of Korean peninsula in East Asia. Adv. Space Res. 2015, 56, 1125-1138. [CrossRef]

17. Hitschfeld, W.; Bordan, J. Errors inherent in the radar measurement of rainfall at attenuating wavelengths. J. Meteorol. 1954, 11, 58-67. [CrossRef] 
18. Snyder, J.C.; Bluestein, H.B.; Zhang, G.; Frasier, S. Attenuation correction and hydrometeor classification of high-resolution, X-band, dual-polarized mobile radar measurements in severe convective storms. J. Atmos. Ocean. Technol. 2010, 27, 1979-2001. [CrossRef]

19. Bringi, V.N.; Chandrasekar, V. Polarimetric Doppler Weather Radar; Cambridge University Press (CUP): Cambridge, UK, 2001.

20. Delrieu, G.; Caoudal, S.; Creutin, J.D. Feasibility of using mountain return for the correction of ground-based X-band weather radar data. J. Atmos. Ocean. Technol. 1997, 14, 368-385. [CrossRef]

21. Carey, L.; Rutledge, S.A.; Ahijevych, D.A.; Keenan, T.D. Correcting propagation effects in C-band polarimetric radar observations of tropical convection using differential propagation phase. J. Appl. Meteorol. 2000, 39, 1405-1433. [CrossRef]

22. Bringi, V.N.; Chandrasekar, V.; Balakrishnan, N.; Zrnic, D.S. An examination of propagation effects in rainfall on radar measurements at microwave frequencies. J. Atmos. Ocean. Technol. 1990, 7, 829-840. [CrossRef]

23. Ryzhkov, A.V.; Diederich, M.; Zhang, P.; Simmer, C. Potential utilization of specific attenuation for rainfall estimation, mitigation of partial beam blockage, and radar networking. J. Atmos. Ocean. Technol. 2014, 31, 599-619. [CrossRef]

24. Krämer, S.; Verworn, H. Improved C-band radar data processing for real time control of urban drainage systems. In Proceedings of the 11th International Conference on Urban Drainage, Edinburgh, UK, 31 August-5 September 2008.

25. Press, W.H.; Teukolsky, S.A.; Vetterling, W.T.; Flannery, B.P. Golden section search in one dimension. In Numerical Recipes in C: The Art of Scientific Computing; Cambridge University Press: Cambridge, UK, 1992.

26. Gunn, K.L.S.; East, T.W.R. The microwave properties of precipitation particles. Q. J. R. Meteorol. Soc. 1954, 80, 522-545. [CrossRef]

27. Delrieu, G.; Andrieu, H.; Creutin, J.-D. Quantification of path-integrated attenuation for X- and C-band weather radar systems operating in mediterranean heavy rainfall. J. Appl. Meteorol. 2000, 39, 840-850. [CrossRef]

28. Feng, L.; Xiao, H.; Wen, G.; Li, Z.; Sun, Y.; Tang, Q.; Liu, Y. Rain attenuation correction of reflectivity for $X$-band dual-polarization radar. Atmosphere 2016, 7, 164. [CrossRef]

29. Le Loh, J.; Lee, D.-I.; Kang, M.-Y.; You, C.-H. Classification of rainfall types using parsivel disdrometer and S-band polarimetric radar in central Korea. Remote. Sens. 2020, 12, 642. [CrossRef]

30. Anagnostou, E.N. A convective/stratiform precipitation classification algorithm for volume scanning weather radar observations. Meteorol. Appl. 2004, 11, 291-300. [CrossRef]

31. Uijlenhoet, R.; Steiner, M.; Smith, J.A. Variability of raindrop size distributions in a squall line and implications for radar rainfall estimation. J. Hydrometeorol. 2003, 4, 43-61. [CrossRef]

32. Oh, Y.-A.; Lee, D.; Jung, S.-H.; Nam, K.-Y. Attenuation correction effects in rainfall estimation at X-band dual-polarization radar: Evaluation with a dense rain gauge network. Adv. Meteorol. 2016, 2016, 1-20. [CrossRef]

33. Leijnse, H.; Uijlenhoet, R.; Stricker, J. Microwave link rainfall estimation: Effects of link length and frequency, temporal sampling, power resolution, and wet antenna attenuation. Adv. Water Resour. 2008, 31, 1481-1493. [CrossRef]

34. Cunningham, J.G.; Zittel, W.D.; Lee, R.R.; Ice, R.L.; Hoban, N.P. Methods for identifying systematic differential reflectivity (ZDR) biases on the operational WSR-88D network. In Proceedings of the 36th Conference on Radar Meteorology, Breckenridge, CO, USA, 16-20 September 2013.

(C) 2020 by the authors. Licensee MDPI, Basel, Switzerland. This article is an open access article distributed under the terms and conditions of the Creative Commons Attribution (CC BY) license (http://creativecommons.org/licenses/by/4.0/). 